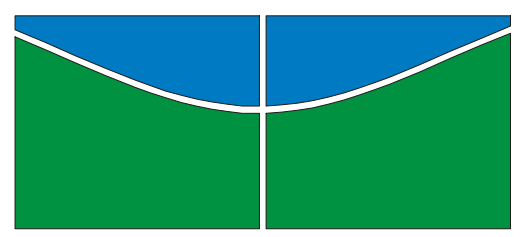

Universidade de Brasília

Centro de Excelência em Turismo

\title{
A UTILIZAÇÃO DAS FERRAMENTAS DE TECNOLOGIA DA INFORMAÇÃO NAS AGÊNCIAS DE VIAGENS: UM ESTUDO DE CASO
}

Dilceia Novak Silva

Maria Elenita Menezes Nascimento

Monografia apresentada ao Centro de Excelência em Turismo da Universidade de Brasília como requisito parcial para a obtenção do certificado de Especialista em Gestão de Negócios em Turismo

Brasília - DF, abril de 2005 
UNIVERSIDADE DE BRASÍLIA

Centro de Excelência em Turismo

Curso de Gestão de Negócios em Turismo

\section{A UTILIZAÇÃO DAS FERRAMENTAS DE TECNOLOGIA DA INFORMAÇÃO NAS AGÊNCIAS DE VIAGÊNS: UM ESTUDO DE CASO}

Dilceia Novak Silva

Banca Examinadora

$\overline{\text { Profa. Dra. Maria Elenita Menezes Nascimento }}$

Prof. Carlos José Rodrigues da Silva, MSc.

Brasília - DF, abril de 2005 
Silva, Dilceia Novak.

A utilização das ferramentas de tecnologia de informação nas agências de viagens : um estudo de caso / Dilceia Novak Silva. Brasília, 2005.

xii, $57 \mathrm{f}$. : il.

Monografia (especialização) - Universidade de Brasília, Centro de Excelência em Turismo, 2005.

Orientadora: Maria Elenita Menezes Nascimento

1. Turismo. 2. Tecnologia da Informação. 3. Agências de Viagens. 


\section{A UTILIZAÇÃO DAS FERRAMENTAS DE TECNOLOGIA DA INFORMAÇÃO NAS AGÊNCIAS DE VIAGÊNS: UM ESTUDO DE CASO}

Comissão Avaliadora

Professora Orientadora

Prof. Carlos José Rodrigues da Silva, MSc.

Brasília - DF, abril de 2005 
Gostaria de agradecer, sinceramente, à minha orientadora, Profa. Dra. Maria Elenita M. Sascimento, pela competência, sensibilidade e a disponibilidade com que sempre me orientou, contribuindo para o aprimoramento intelectual e profissional que acredito ter adquirido através do vínculo estabelecido. 
Para o meu marido, $\mathcal{N}$ elson da Silva, cujo apoio, carinho e incentivo foram fundamentais para a elaboração desta monografia. 


\section{Resumo}

A Tecnologia da Informação - TI vem revolucionando o mundo, criando novas formas de interação entre pessoas, organizações e negócios. O setor de agências de viagens é um segmento que muito tem se beneficiado dos serviços suportados pela TI. O objetivo deste trabalho é verificar o comportamento das agências de viagens em relação à utilização das novas tecnologias. Os dados foram coletados junto a vinte agências de viagens, representando $20 \%$ do total das agências de viagens do DF. O resultado da análise de dados mostrou um padrão diferenciado no uso da TI por parte das agências de viagens. Verificou-se que os recursos da TI podem ser explorados de forma mais intensiva a fim de se atingir um padrão eficiente de uso, aumentado a posição competitiva das agências de viagens.

Palavras-chave: Turismo, Tecnologia da Informação, Agências de Viagens. 


\begin{abstract}
The Information Technology has been revolutionizing the world, it created new iteration forms among people, organizations and businesses. The travel agencies is a segment that a lot has a beneficiary of the services supported by the Information Technology. The aim of this work is to verify the behavior of the travel agencies in relations to use of the new technologies. The data were collected twenty travel agencies close to representing $20 \%$ of the total of travel agencies of Federal District (DF). The result of the analyzes of data showed a pattern differentiated in use of Information Technology on the part of travel agencies. One verify that resources of Information Technology can be explored in a more intensive way in order to reach a pattern of efficient use, increasing the competitive position of the travel agencies.
\end{abstract}

Key words: Tourism, Information Technology, Travel Agencies 


\section{SUMÁRIO}

RESUMO

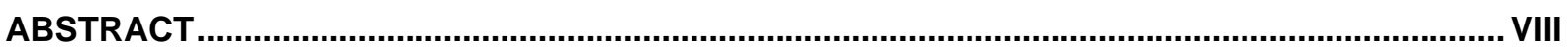

LISTA DE QUADROS

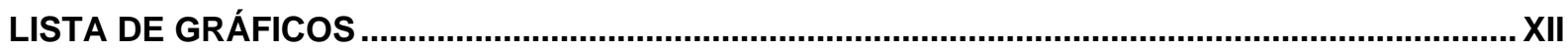

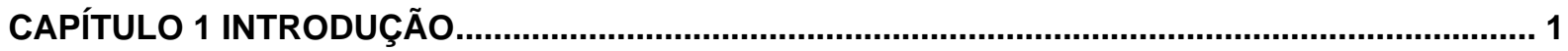

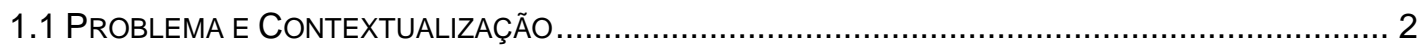

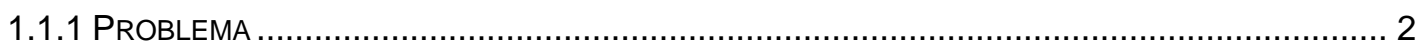

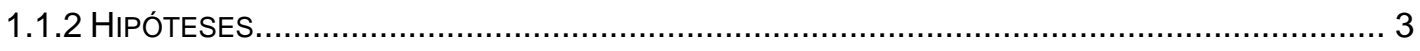

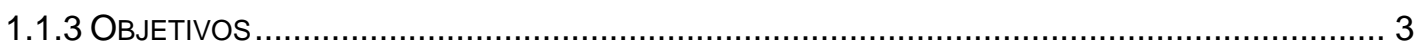

1.1.4 JUSTIFICATIVA(S) E REFERENCIAL TEÓRICO ….......................................................... 4

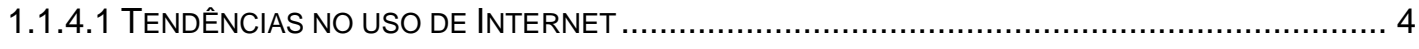

1.1.4.2 PONTOS CRÍTICOS DA DISCUSSÃO E PREOCUPAÇÕES .................................................. 7

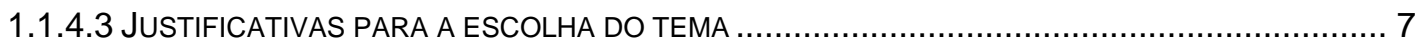

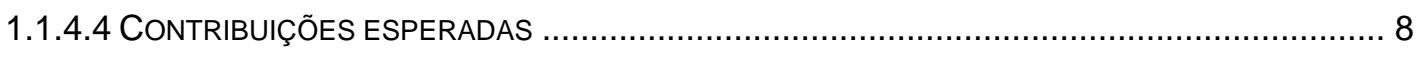

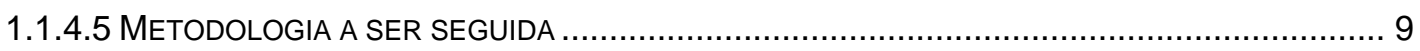

CAPÍTULO 2 A IMPORTÂNCIA DA TI PARA O TURISMO

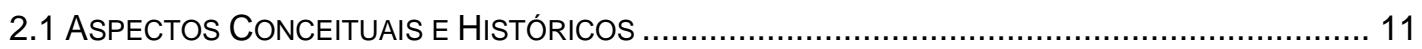

2.2 - SITUAÇÃO ATUAL DAS AGÊNCIAS DE VIAGENS FRENTE ÀS NOVAS TECNOLOGIAS ................. 14

2.3 A IMPORTÂNCIA DA TI PARA AS AGÊNCIAS DE VIAGENS................................................. 17

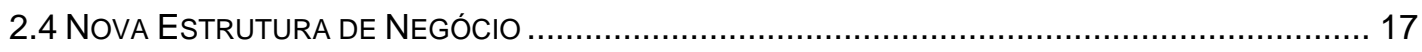

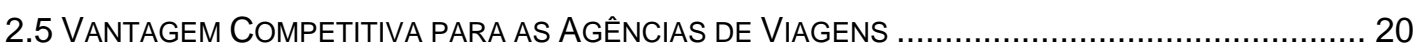

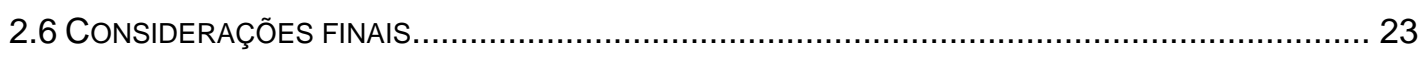

CAPÍTULO 3 TECNOLOGIA DA INFORMAÇÃO NAS AGÊNCIAS DE VIAGENS.......................... 24

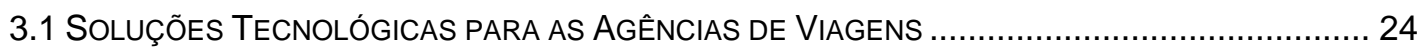

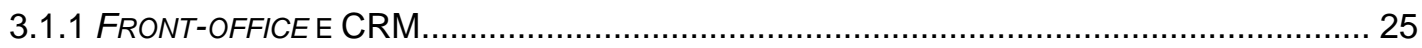

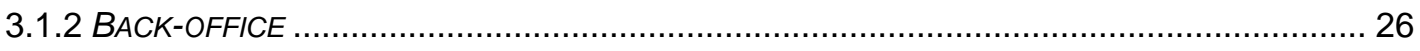

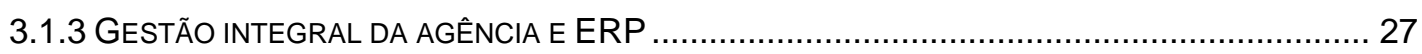

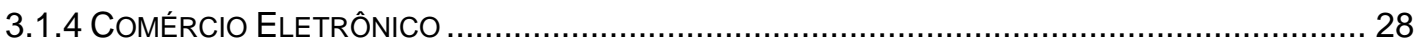

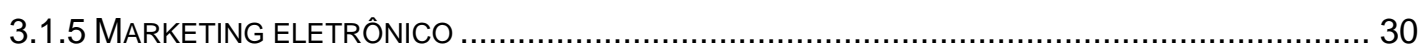

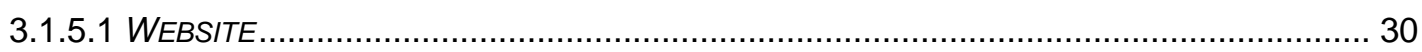

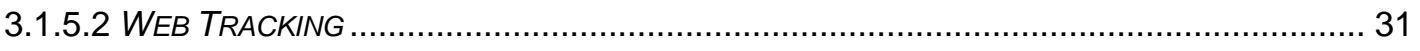

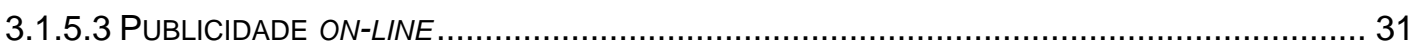

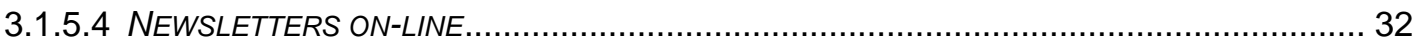




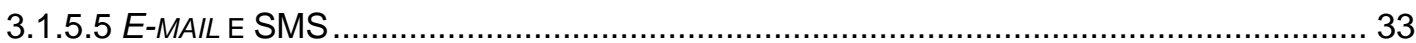

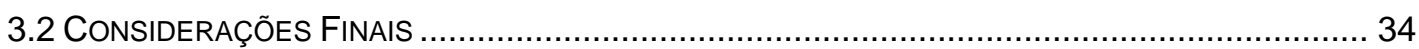

CAPÍTULO 4 ANÁLISE DE DADOS ........................................................................................... 36

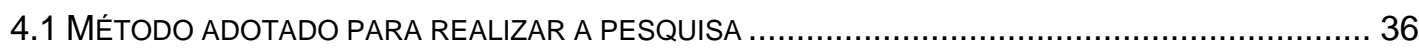

4. 2 HISTÓRICO DO FUNCIONAMENTO DAS AGÊNCIAS DE VIAGENS .................................... 38

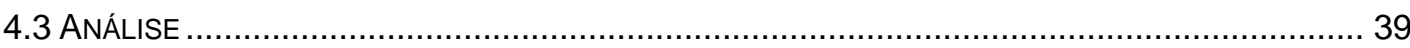

4.4 UTILIZAÇÃO DAS FERRAMENTAS DA TI PELAS AGÊNCIAS DE VIAGENS .............................40

4.5 UTILIZAÇÃO DAS ESTRATÉGIAS DE PROMOÇÃO ELETRÔNICA DE MARKETING PELAS

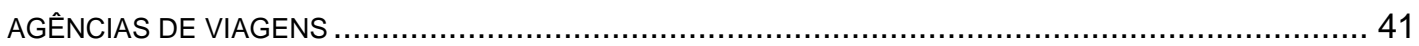

4.6 PERFIL dOS PROFISSIONAIS QUE ATUAM NAS AGÊNCIAS DE VIAGENS. ............................ 46

4.7 A TECNOLOGIA DA INFORMAÇÃO E A FIDELIZAÇÃO DOS CLIENTES ................................ 47

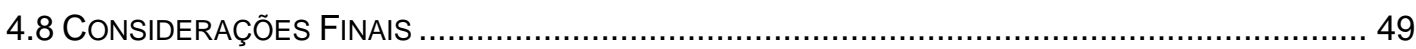

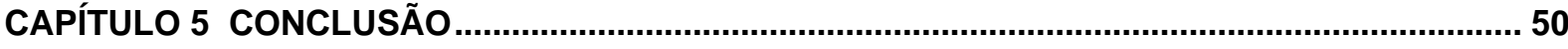

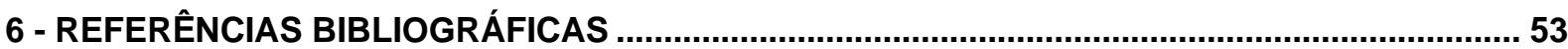

APÊNDICE I .................................................................................................................... 56 


\section{Lista de Quadros}

Quadro 1.1 Quantidade de Pessoas Conectadas a Web no Brasil - Série Histórica 1997 2004. 5

Quadro 1.2 Pesquisa sobre utilização da Internet nas agências de viagens 6

Quadro 2.1 As cinco características essenciais da sociedade do conhecimento (nova

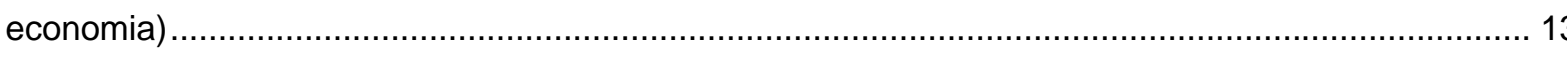

Quadro 4.1 Histórico de funcionamento das agências de viagens .................................................... 38

Quadro 4.2 Estratégias de promoção eletrônica de marketing utilizadas pelas agências de

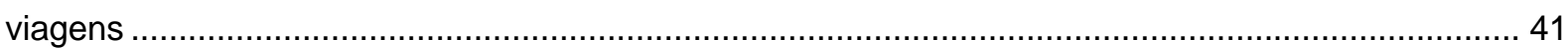

Quadro 4.3 Obstáculos para implementação de novas tecnologias................................................. 43

Quadro 4.4 Meios utilizados para se obter conhecimentos sobre inovações tecnológicas ............... 45

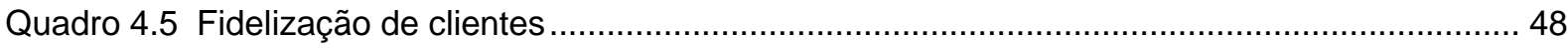




\section{Lista de Gráficos}

Gráfico 4.1 Quantidade de funcionários nas agências de viagem...................................................... 39

Gráfico 4.2 Uso das ferramentas de TI pelas agências de viagens ............................................... 42

Gráfico 4.3 Obstáculos para implementação das novas tecnologias ................................................ 44 


\section{Capítulo 1 Introdução}

O setor do turismo apresenta-se em constante desenvolvimento e os meios de informação e a tecnologia representam um papel importante para este mercado. A utilização da Tecnologia da Informação ( $\mathrm{TI})$, pelas empresas do setor turístico, está cada vez mais intensa. A TI é considerada por muitos, como uma das mais poderosas ferramentas para alavancar negócios. Os avanços tecnológicos têm possibilitado a muitas empresas modificarem seu perfil competitivo, além de conquistarem maiores fatias de mercado.

De acordo com DI SERIO \& MAIA (2004), a TI modificou sensivelmente o relacionamento entre organizações, fornecedores e clientes, assim como as modalidades internas de organizar e tratar os fluxos de informação. Essas mudanças foram percebidas pelas empresas turísticas desde a integração/interconexão possibilitadas pela Internet e em decorrência de novos e sofisticados sistemas operacionais, com destaque para os sistemas de reservas de hotéis, passagens aéreas e carros.

O setor de agências de viagens é um segmento que muito tem se beneficiado dos serviços suportados pela TI. A utilização das ferramentas da $\mathrm{TI}$ resulta em obter vantagens competitivas, na medida em que proporciona redução de custos, ganho de tempo e é um meio eficaz de obtenção de compartilhamento de informação. As tecnologias baseadas na Internet tem sido fundamentais para o gerenciamento das agências de viagens e interação com os clientes. 


\subsection{Problema e Contextualização}

Este capítulo apresenta a introdução geral do trabalho, o problema, as hipóteses, os objetivos da pesquisa, as justificativas e a metodologia a ser seguida.

\subsubsection{Problema}

A Tecnologia da Informação (TI) tornou-se uma ferramenta indispensável para manter a competitividade das empresas no mercado. Ela também pode ser um fator de ameaça, principalmente para as pequenas e médias empresas, uma vez que estas, em geral, dispõem de recursos limitados, não apenas financeiros, como também no que se refere à capacitação dos profissionais que atuam nessas empresas. Parte-se do princípio que o uso de canais eletrônicos exige treinamento, especialização e segmentação.

Em termos de implantação de sistemas informatizados, as agências de viagens, como em geral, são empresas de pequeno porte, apresentam as mesmas dificuldades. Segundo pesquisa realizada pela Associação Brasileira das Agências de Viagens - ABAV, em 1999, sobre a presença das agências de viagens na Internet, tendo como base 4672 agências associadas, constatou-se que $71,4 \%$ dessas empresas ainda não estavam conectadas à Internet. 0 objetivo da presente pesquisa é verificar o comportamento das agências de viagens em relação à utilização das novas tecnologias. Assim, essa pesquisa está permeada pelas seguintes questões:

- Como as novas tecnologias estão sendo incorporadas pelas agências de viagens?

- Por que algumas agências de viagens ainda não incorporaram a TI em seus negócios?

- Os agentes de viagens estão preparados para organizar planos de viagens para os clientes e oferecer aconselhamento e informações 
especializadas sobre os destinos, ou agem, em geral, somente como vendedores de passagens?

\subsubsection{Hipóteses}

- Os empresários das agências de viagens no Brasil, ainda não estão utilizando os recursos da TI em toda sua potencialidade;

- Supõe-se que algumas agências de viagens ainda não aderiram à TI por falta de recursos financeiros, ou por não conseguirem visualizar os benefícios que os meios de comunicação, como a Internet, podem trazer para seu negócio;

- Acredita-se que os agentes de viagens, em geral, não conhecem os destinos turísticos que vendem, se restringem apenas a vender passagens, não podendo assim, passar informações adequadas aos clientes.

\subsubsection{Objetivos}

- Objetivo geral:

O objetivo da presente pesquisa é verificar o comportamento das agências de viagens em relação à utilização das novas tecnologias.

- Objetivos específicos:

a) Realizar um estudo sobre as mudanças provocadas pela inserção da Internet nas agências de viagens;

b) Verificar se as agências de viagens estão utilizando a Internet de forma eficaz a fim de aumentar suas posições competitivas;

c) Mostrar quais são as mudanças de estratégias necessárias para utilização dessa tecnologia de forma a provocar resultados eficazes nas organizações; 
d) Verificar o percentual de agências de viagens do DF que estão conectadas à Internet.

\subsubsection{Justificativa(s) e Referencial teórico}

\subsubsection{Tendências no uso de Internet}

O aumento do número de pessoas conectadas à Internet ocorre de uma forma diferenciada em cada país, dependendo de variáveis diversas como: renda da população, nível educacional, grau de segurança disponibilizado, desenvolvimento das empresas, dentre outras.

A geração atual passa por um momento de transição, pois está presenciando o início do mundo virtual e tem que se adaptar à essa nova realidade, em um processo nem sempre tranqüilo. As gerações futuras já irão se deparar com um mundo conectado, desta forma, a realização de transações on-line será percebida com maior facilidade em relação à geração atual. $\mathrm{O}$ fato é que o processo de familiarização a essa nova realidade, que para geração atual é, em geral, um passo difícil, provavelmente será para as futuras gerações um processo normal, de tal forma que até a compra on-line ocorrerá de forma natural.

Com o advento da Internet e o crescente número de usuários, as companhias aéreas tiveram a oportunidade de estabelecer uma relação mais próxima com os clientes finais. Dessa forma, a Internet contribuiu para reduzir a importância dos intermediários, como as agências de viagens, levando a uma queda em suas comissões. Hoje é possível comprar e reservar bilhetes aéreos diretamente da companhia aérea e em geral a um preço mais acessível do que o encontrado na maioria das agências de viagens.

Neste sentido, as agências de viagens não podem mais utilizar velhas receitas de épocas passadas, sob pena de total ineficácia. Atualmente, as empresas, em geral, precisam sempre estar surpreendendo os seus clientes e oferecendo algo a mais para eles, a fim de permanecerem e consolidarem sua 
presença no mercado. No entanto, os agentes de viagens, em geral, pouco fazem a fim de melhorar seus serviços, pois não se sentem ameaçados pelo fato de as companhias aéreas poderem estabelecer um contato mais próximo com os clientes finais.

A tendência do aumento de usuários conectados à Internet no Brasil pode ser confirmada no quadro 1.1:

Quadro 1.1

Quantidade de Pessoas Conectadas a Web no Brasil - Série Histórica $1997-2004$

\begin{tabular}{|l|c|c|c|c|r|}
\hline $\begin{array}{c}\text { Data da } \\
\text { Pesquisa }\end{array}$ & $\begin{array}{c}\text { População } \\
\text { total IBGE }\end{array}$ & $\begin{array}{c}\text { Internautas } \\
\text { (milhões) }\end{array}$ & $\begin{array}{c}\% \text { da } \\
\text { População } \\
\text { Brasileira }\end{array}$ & $\begin{array}{c}\mathbf{N}^{\circ} \text { de } \\
\text { Meses } \\
\text { (base=jan/96) }\end{array}$ & $\begin{array}{c}\text { Crescimento } \\
\text { Acumulado } \\
\text { (base=jul/97) }\end{array}$ \\
\hline 2004/jan & 178,4 & 20,05 & $11,5 \%$ & 95 & $1.686 \%$ \\
\hline 2003 /jan & 176,0 & 14,32 & $8,1 \%$ & 83 & $1.143 \%$ \\
\hline 2002/ago & 175,0 & 13,98 & $7.9 \%$ & 78 & $1.115 \%$ \\
\hline 2001/set & 172,3 & 12,04 & $7.0 \%$ & 67 & $947 \%$ \\
\hline 2000/nov & 169,7 & 9,84 & $5.8 \%$ & 59 & $756 \%$ \\
\hline 1999/dez & 166,4 & 6,79 & $7.1 \%$ & 48 & $490 \%$ \\
\hline 1998/dez & 163,2 & 2,35 & $1.4 \%$ & 36 & $104 \%$ \\
\hline 1997/dez & 160,1 & 1,30 & $0.8 \%$ & 24 & $13 \%$ \\
\hline 1997/jul & 160,1 & 1,15 & $0.7 \%$ & 18 & - \\
\hline
\end{tabular}

Compilado por www.e-commerce.org.br / fonte: pesquisas diversas / população: variações anuais estimadas

Observa-se que de julho de 1997, período em que o mercado ultrapassava a marca de um milhão de usuários, até jan/2004, houve um crescimento acumulado de mais de $1.500 \%$ no número de pessoas conectadas à Web, o que fazendo uma média simples, representa um expressivo crescimento de 19\% ao mês. Outro dado relevante é a penetração da Internet junto à população, que na última pesquisa atingiu 11,5\%.1

${ }^{1}$ A expansão de um mercado depende muito da conjuntura econômica do período em questão, além de variáveis sócio econômicas de cada país. O grau de penetração serve como um importante indicador do espaço de crescimento disponível no mercado. Quanto maior é a distância do limite de $100 \%$ da população, maior é a possibilidade de crescimento e nesse aspecto, os números mostram claramente que o mercado brasileiro tem um enorme espaço a ser ocupado. 
No que se refere às agências de viagens, a última pesquisa da $A B A V$ Nacional, ocorrida em $1999^{2}$, apontou que $28.6 \%$ delas estavam conectadas à Internet. O quadro 1.2 apresenta a pesquisa sobre o acesso a Internet nas agências de viagens em 1999.

Quadro 1.2

Pesquisa sobre utilização da Internet nas agências de viagens

\begin{tabular}{|l|c|}
\hline Há quanto tempo possui acesso à Internet & $\%$ \\
\hline Não possui & $\mathbf{7 1 , 4}$ \\
\hline 1 ano ou menos & $\mathbf{1 7 , 5}$ \\
\hline 2 anos ou menos & $\mathbf{8 , 5}$ \\
\hline 3 anos ou menos & $\mathbf{2 , 3}$ \\
\hline 4 anos ou menos & $\mathbf{0 , 3}$ \\
\hline 5 anos ou menos & $\mathbf{0 , 1}$ \\
\hline Total & $\mathbf{1 0 0 , 0 0}$ \\
\hline
\end{tabular}

Fonte: ABAV Nacional - 1999

Considerando o período de dez/99 a jan/2004, calculou-se através do quadro 1.1, que o crescimento de pessoas com acesso à Web foi de 203\%. Portanto, se for aplicado essa taxa ao caso das agências de viagens pode-se inferir que atualmente $86,65 \%$ das agências acessam a Internet. Esse número parece não corresponder à realidade. Espera-se que o percentual seja menor, dado as características das agências.

Outra pesquisa que faz a estimação do percentual das agências de viagens com acesso a Internet foi realizada pelo SEBRAE em 2003. De acordo com SANTOS \& HASSAN (2003) essa pesquisa revelou que nos últimos dez anos, o nível de inclusão digital das micro e pequenas empresas, no Estado de São Paulo, saltou de 19\% para 47\%. Esse estudo foi realizado junto a 1163 estabelecimentos de micro e pequeno porte, em 41 municípios paulistas. A pesquisa identificou, ainda, que $54 \%$ das empresas entrevistadas acessam a

${ }^{2}$ Segundo a ABAV, a última pesquisa sobre a utilização da Internet nas agências de viagens foi realizada em 1999 e depois desta data não houve mais atualização. 
Internet, seja na empresa com microcomputadores (38\%), fora da empresa com equipamento próprio (4\%) ou fora da empresa sem microcomputador (12\%). Das micro e pequenas empresas não informatizadas (53\%), mais da metade (64\%) afirmou não ver real necessidade ou benefício nesta ferramenta. Por se tratar do caso mais apropriado para as agências, pode-se acreditar que esse percentual esteja mais próximo do caso das agências, implicando que o crescimento de agências com acesso a Internet é menor do que a taxa de aumento de pessoas conectadas.

\subsubsection{Pontos críticos da discussão e preocupações}

Segundo DI SERIO \& MAIA (2004), dentre os fatores considerados críticos ao posicionamento das organizações para a era da Informação, podese identificar: a rapidez da evolução dos meios de comunicação e a necessidade de atualização constante da infra-estrutura tecnológica; as questões de segurança, a inexistência de uma cultura de Internet e a falta de capacitação tecnológica por parte de alguns profissionais que atuam nas empresas do turismo.

Associando-se a isso, o crescente número de pessoas conectadas a Internet permitiu que as companhias aéreas chegassem com mais facilidade ao consumidor final, tirando grande parte do negócio das agências de viagens e reduzindo de forma drástica suas comissões. A Internet possibilita o acesso às informações 24 horas por dia, e 365 dias por ano, sem a dependência de horário comercial ou da disponibilidade das agências de viagens. Portanto, essa ferramenta serve como um canal de comunicação direta com os clientes.

\subsubsection{Justificativas para a escolha do tema}

Pode-se citar como justificativa para essa pesquisa o avanço da $\mathrm{TI}$ e a importância de sua utilização pelas agências de viagens como fator de inovação e garantia de sobrevivência neste mercado competitivo. 
Não só no Brasil, como no resto do mundo, vem crescendo, a cada dia, o uso da TI. Isso tem possibilitado a interligação de áreas de conhecimento, fornecedores, clientes, que processam grandes números de transações de forma rápida e, muitas vezes, personalizadas, observa ALBERTIN (1999).

Em geral, existe uma certa resistência por parte de algumas empresas em aderir às novas tecnologias e ao comércio eletrônico como um instrumento de apoio à realização de negócios. Esse comportamento pode ameaçar a sobrevivência das empresas que resistirem em se adaptar as novas maneiras de se fazer negócios proporcionadas pela Internet.

Pelo estudo realizado até o presente pode-se inferir que os avanços tecnológicos trazem muito mais benefícios às agências de viagens do que a forma tradicional de gerir essas empresas. Os argumentos que nos levam a fazer tais afirmações estão centrados nos seguintes benefícios para as agências de viagens: busca de novos clientes, melhor conhecimento dos hábitos e comportamentos dos consumidores, melhoria no atendimento que pode passar a ser personalizado e possibilidade de disputa equilibrada no mercado. Vale destacar que a implementação da TI, também, pode trazer aspectos negativos às organizações, esses aspectos serão discutidos no decorrer do trabalho.

\subsubsection{Contribuições esperadas}

Por meio dos resultados da pesquisa, espera-se disponibilizar aos formuladores de políticas estratégicas das agências de viagens, que ainda não aderiram a TI, os benefícios que os avanços tecnológicos podem proporcionar para o seu negócio, tendo em vista que a TI, se bem utilizada, pode reduzir custos, potencializar as vendas, criar condições para conquistar novas fatias de mercado e conseqüentemente aumentar os lucros.

De acordo com MARÍN (2004), a tecnologia pode exercer um papel decisivo no desempenho das agências de viagens, ajudando-as a atingir seus objetivos, aumentando a produtividade e permitindo que os profissionais se concentrem nas atividades que agregam valor e diferenciação, assim como no 
gerenciamento estratégico da empresa. Da mesma forma, observa PORTER (2001), a Internet tem sido consagrada como uma tecnologia que provê oportunidades para as organizações estabelecerem posições estratégicas diferenciadas.

\subsubsection{Metodologia a ser seguida}

A metodologia a ser adotada neste trabalho constitui-se de pesquisa bibliográfica e estudo de caso. De acordo com YIN (2001), o estudo de caso é um questionamento empírico que investiga um fenômeno contemporâneo com seus contextos de vida real, quando as fronteiras entre fenômeno e contexto não são claramente evidentes, e nos quais fontes múltiplas de evidência são usadas. Para COSTA (2001p. 62), o estudo de caso é limitado a uma ou poucas unidades, que podem ser uma pessoa, uma família, um produto, uma instituição, uma comunidade ou mesmo um país. É uma pesquisa detalhista e profunda.

A definição por este método de pesquisa baseado em estudo de caso se justifica pelo fato de que existem poucas pesquisas em relação à utilização da TI nas agências de viagens. Estima-se que o uso da Internet no setor do turismo ainda não atingiu toda a sua potencialidade em virtude de que faz relativamente pouco tempo que as indústrias do turismo passaram a fazer uso da Internet.

A aplicação da metodologia de estudo de caso será realizada por meio de questionário, que servirá como instrumento de coleta de dados. O questionário conterá perguntas fechadas e abertas e será enviado por correio eletrônico. Segundo BARROS \& LEHFELD (2000), perguntas fechadas são aquelas questões que apresentam categorias ou alternativas de respostas fixa e perguntas abertas são aquelas que levam o informante a responder livremente com frases ou orações. Os dados serão coletados junto a 20 agências de viagens do DF. Como critério de seleção, será utilizada a técnica de amostragem aleatória simples, através de sorteio. De acordo com COSTA (2001), neste tipo de amostra a premissa é de que cada componente da 
população estudada tem a mesma chance de ser escolhida para compor a amostra. Portanto, esta técnica evita uma escolha deliberada do pesquisador.

Esse trabalho foi dividido em 5 capítulos. O capítulo 1 apresenta a introdução geral do trabalho, contempla o problema, as hipóteses, os objetivos da pesquisa, as justificativas e a metodologia a ser seguida. O capítulo 2 tem como objetivo explorar a relação entre o turismo e a TI. Desta forma, busca-se discutir a importância da TI para o turismo, como uma ferramenta essencial para potencializar vendas e reduzir custos. O capítulo 3 faz uma explanação de como as agências de viagens podem agir para obter vantagem competitiva na era da informação. Atualmente, com o advento da Internet e a democratização da informação, muitos clientes chegam à agência de viagens com uma gama de informações maior do que a própria agência. Sendo assim, essas empresas devem estar preparadas para transmitir aos clientes informações que vão além daquelas obtidas na Internet ou através de folhetos. O capítulo 4 identifica cinco soluções tecnológicas que estão à disposição das agências de viagens e orienta os profissionais do setor sobre a utilização dessas ferramentas. No capítulo 5 realizou-se a análise de dados que foram coletados por meio de entrevistas realizadas junto às agências que fizeram parte da amostra. No capítulo 6 apresentam-se as considerações finais, ressaltando-se algumas agências conseguem tirar melhor proveito dos recursos oferecidos pela tecnologia de informação e, assim, nota-se que existe um espaço para a exploração mais intensiva da TI a fim de se atingir um padrão eficiente de uso. 


\section{Capítulo 2}

\section{A Importância da TI para o Turismo}

Esse capítulo tem como objetivo explorar a relação entre o turismo e a TI. Desta forma, busca-se discutir a importância da TI para o turismo, demonstrando que, nesta era globalizada, a Tecnologia da Informação constitui-se em um instrumento fundamental para a competitividade das empresas deste setor, sobretudo por sua capacidade de criar estratégias que facilitam o processo de compra, venda e a troca de informações. Além disso, esse capítulo apresenta a forma pela qual as agências podem agir para continuarem sendo intermediarias importantes para os clientes.

\subsection{Aspectos Conceituais e Históricos}

Nesta seção são apresentados alguns aspectos conceituais sobre turismo e a TI. Além disso, discute-se a questão do surgimento da TI no Brasil e apresenta-se as principais características da Sociedade do Conhecimento em contraponto às características da Sociedade Industrial, deixando claro a necessidade de uma nova política, diferenciada da anterior.

O turismo é uma atividade em pleno crescimento, com perspectivas bastante promissoras. Este setor é considerado de extrema importância para o crescimento da economia de um país, dado o seu potencial de geração de emprego e renda. Além disso, o turismo contribui de forma significativa para aumentar o PIB de cada país, melhorando a qualidade de vida da população. DE LA TORRE (1992, p. 19), conceitua o turismo da seguinte forma: 


\begin{abstract}
"Turismo é um fenômeno social que consiste no deslocamento voluntário e temporário de indivíduos ou grupos de pessoas que, fundamentalmente por motivos de recreação, descanso, cultura ou saúde, saem do seu local de residência habitual para outro, no qual não exercem atividades lucrativas ou remuneradas, gerando múltiplas interrelações de importância social, econômica e cultural".
\end{abstract}

Diante da complexidade que envolve o turismo, a TI vem desempenhando um papel fundamental para o desenvolvimento deste setor. $\mathrm{Na}$ chamada era da Informação, a integração viabilizada pela Internet e outras tecnologias interativas estão promovendo grandes mudanças no mercado. Essas tecnologias estão permitindo a integração e o desenvolvimento da distribuição global de serviços turísticos.

Para CRUZ (1997, p. 160) "tecnologia da informação é o conjunto de dispositivos individuais, como "hardware", "software", telecomunicações ou qualquer outra tecnologia que faça parte ou gere tratamento da informação, ou ainda, que a contenha".

O desenvolvimento da (TI) mudou a forma de como as pessoas trocam as informações, causando uma nova revolução. O século $X X I$ fica caracterizado como a Era da Informação. O' CONNOR (2001, p. 15) justifica: "Seu poder [da tecnologia da informação] permite que a informação seja gerenciada de forma mais efetiva e transportada pelo mundo todo quase imediatamente".

No Brasil, a TI tomou impulso a partir do advento da Sociedade da Informação. De acordo com TAKAHASHI (2000), o Programa Sociedade da Informação resultou de um trabalho iniciado em 1996, pelo Conselho Nacional de Ciência e Tecnologia-CNPq. Este programa teve como finalidade lançar os alicerces de um projeto estratégico, de amplitude nacional, para integrar e coordenar o desenvolvimento e a utilização de serviços avançados de computação, comunicação e informação, e de suas aplicações na sociedade, de forma a alavancar a pesquisa e a educação, bem como assegurar que a economia brasileira tivesse condições de competir no mercado mundial.

A TI nem sempre esteve presente na sociedade, nos meios de produção. No século XVI, o conhecimento não era considerado um fator relevante para a geração de riqueza das nações. Os mercantilistas viam na obtenção do ouro e da prata a maneira mais importante de enriquecer um país. 
No século XVIII, Adam Smith considerava a divisão social do trabalho como sendo a verdadeira fonte de riqueza das nações. Para ele, a produção nacional podia crescer através da divisão do trabalho, criando especializações capazes de aumentar a produtividade e fazer baixar o preço das mercadorias.

Atualmente, a acumulação de metais preciosos deixou de ser um fator preponderante. A divisão social do trabalho continua sendo um elemento essencial para geração de riqueza de um país, contudo, ela incorporou a TI como um elo primordial para o desenvolvimento e para a geração de renda de qualquer país.

De acordo com CAVALCANTI \& GOMES (2001), na era da nova economia, ou economia baseada em conhecimento, as atividades que agregarão mais valor, que gerarão mais riqueza para uma nação, serão aquelas geradas pela inovação, e esta principalmente pela capacidade de utilizar o conhecimento agregado aos produtos e serviços oferecidos. O que importa agora para o aumento da produtividade é o trabalho intelectual e para isso é necessário criar mecanismos para gerir esse conhecimento.

De uma maneira sintética aponta-se, no quadro 2.1, cinco aspectos essenciais para caracterizar a sociedade do conhecimento (nova economia):

\section{Quadro 2.1}

As cinco características essenciais da sociedade do conhecimento (nova economia)

\begin{tabular}{lll}
\hline \multicolumn{1}{c}{ Atributos } & \multicolumn{1}{c}{ Paradigma industrial } & Paradigma do conhecimento \\
- Modelo de produção & - Economia de escala & - Flexível \\
- Pessoas & - Mão de obra especializada & - Polivalente e empreendedor \\
- Tempo & - Grandes tempos de resposta & - Tempo real \\
- Espaço & - Limitado e definido & - llimitado e indefinido \\
- Massa & - Tangível & - Intangível \\
\hline
\end{tabular}

Fonte: Centro de Referência em Inteligência Empresarial CRIE - COPPE/UFRJ

O quadro 2.1 contrapõe o paradigma industrial com o paradigma do conhecimento. Hoje os consumidores são mais exigentes, não aceitam serviços padronizados, buscam serviços customizados que atendam suas necessidades individuais. As profissões também passaram por um processo 
de mudança acentuada, dado o maior valor atribuído ao conhecimento. Desta forma, o profissional que está se preparando para trabalhar na nova economia deve ser flexível, polivalente e criativo. O tempo também é considerado uma variável essencial nesta era globalizada. As pessoas estão se tornando cada vez mais intolerantes a perda de tempo, elas desejam obter informações precisas e em tempo real. O sucesso de uma organização não está vinculado somente à posse de bens tangíveis (máquinas, imóveis, recursos financeiros), os bens intangíveis também são importantes. Por isso a necessidade de se valorizar o ensino, de preservar os recursos humanos, possuidores de conhecimento, espírito empreendedor e criatividade.

\section{2 - Situação atual das agências de viagens frente às novas tecnologias}

Nesta seção discute-se a situação atual das agências de viagens frente às novas tecnologias. A nova era do turismo, marcada pelo aumento da competitividade, requer novos tipos de sistemas, que possibilitem disponibilizar as informações de maneira rápida, fácil e a baixos custos. Da mesma forma, flexibilidade, criatividade e a capacidade de iniciativa são atributos essenciais do profissional que está se formando para trabalhar neste mercado competitivo.

O avanço tecnológico e a globalização têm exigido uma nova postura das agências de viagens. Antes, essas empresas, em geral, tinham espaço de atuação e lucro praticamente garantidos. Essa situação permitiu que as agências trabalhassem, por muito tempo, com uma margem de tolerância, na qual o desperdício e os erros, dentro de certos percentuais, eram aceitos.

Hoje, as agências de viagens encontram-se pressionadas a rever suas estratégias de ação, em virtude do surgimento de um novo contexto: clientes mais exigentes, comissões em queda e maior concorrência. De acordo com MAYA \& OTERO (2002), atualmente, os clientes passaram a desempenhar um papel inimaginável algum tempo atrás, passaram a definir não apenas o que desejam comprar, mas também onde comprar, como comprar, quando receber e, ainda, quanto estão dispostos a pagar. 
Além disso, as agências de viagens se encontram, atualmente, em um ambiente de grande competição, comparativamente à década anterior, pois as companhias aéreas estão estabelecendo relacionamentos diretos com os consumidores finais, fato que deixa os intermediários, como as agências de viagens, em uma situação delicada. A figura 2.1 mostra que as companhias aéreas (prestadoras de serviços) e as agências (varejo de serviços) estão em uma disputa acirrada para estabelecer relacionamentos diretos com os consumidores.

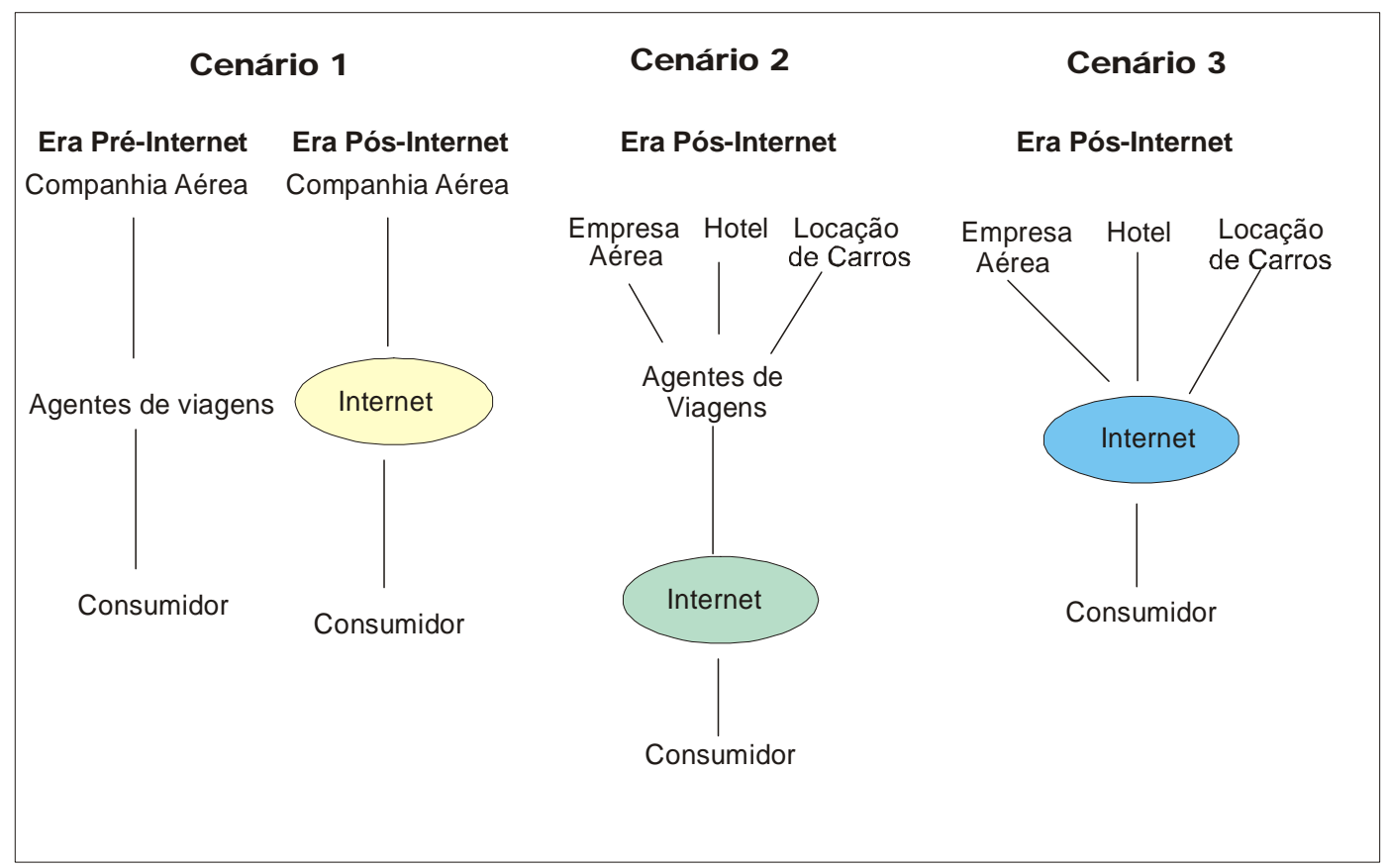

Figura 2.1 - A desintermediação e reintermediação proporcionada pela Internet Baseada em VASSOS, 1998.

Pode-se notar pela figura 2.1, que no cenário 1 os agentes de viagens estão presentes apenas na era pré-Internet. No cenário 2, os agentes de viagens estão fazendo a intermediação entre os fornecedores e os consumidores finais através da Internet. O cenário 3 demonstra uma relação direta do consumidor final com os fornecedores. Essa relação é suportada pela Internet. Cada vez mais os fornecedores buscarão negociar diretamente com os clientes finais a fim de reduzir custos.

Neste contexto, as agências de viagens encontram-se, atualmente, em um momento de questionamento de suas atividades, em decorrência da disseminação da Internet. De acordo com ULYSSÉA (et al., 2002), a nova era 
do turismo requer novos tipos de sistemas de gestão, que respondam, através de maior flexibilidade e segmentação, aos diferentes desejos e necessidades dos clientes, com estratégias completas e claras de desenvolvimento turístico.

Diante dessa realidade, e a fim de manterem suas operações em um mercado cada vez mais disputado, os agentes de turismo precisam aproveitar o potencial da TI para reverter essa situação em seu favor. Vale destacar que, para satisfazerem as necessidades do mercado, as organizações terão que aderir aos avanços tecnológicos desde "hardware" até "software" e recursos humanos, indispensáveis para identificar a demanda e a oferta turística que podem oferecer maior satisfação aos clientes.

Vale ressaltar que por si só os recursos da informática não são fatores de sucesso se o usuário não sentir como real o valor ou o retorno do sistema ou instrumento que deve utilizar em suas atividades. Considera-se que é o recurso humano que definirá as necessidades e em função destas, indicará programas (e "softwares") necessários, como os recursos materiais (equipamentos), observa MAÑAS (1999).

A TI está disponível em muitas organizações, porém, o diferencial está em saber como utilizá-la. No caso do turismo, é preciso saber trabalhar de forma criativa, inovadora e empreendedora, com profissionais capacitados, que tenham habilidades para identificar oportunidades, para se comunicar, negociar, resolver problemas e adquirir informações. O turismo deixou de ser uma atividade para amadores. De acordo com TAKAHASHI (2000, p. 7), "na nova economia, não basta dispor de uma intra-estrutura moderna de comunicação; é preciso competência para transformar informação em conhecimento".

Nota-se que o setor do turismo estará cada vez mais vinculado a $\mathrm{Tl}$, sendo este, um dos fatores que poderá proporcionar um impulso maior para o desenvolvimento deste setor, tornando os serviços melhores em relação à redução de custos, melhoria da qualidade no atendimento e incremento aos produtos e serviços. Daí a importância em aderir às novas tecnologias. 


\subsection{A Importância da TI para as agências de viagens}

Esta seção apresenta a importância da TI para as agências de viagens. Ela se destaca hoje, como uma das mais poderosas ferramentas para alavancar negócios, proporcionar redução de custos, agilidade e acesso mais direto aos consumidores, entre outros benefícios.

Segundo O'CONNOR (2001), o turismo é considerado como uma grande indústria pelo mundo inteiro. É um importante representante econômico e movimenta diversos setores da economia, contribuindo para o desenvolvimento de novas áreas ou para outras que já apareciam no mercado, porém não se destacavam. Da mesma forma afirma FERNANDES \& COELHO (2002, p. 4), "o turismo tem evoluído substancialmente ao longo do tempo, especialmente a partir da segunda metade do século XX, e é considerado nos dias de hoje, o segmento que exibe um dos maiores crescimentos no mundo dos negócios".

Neste contexto, a TI representa um papel fundamental para as agências de viagens. Ela é reconhecida como um instrumento de apoio a essas empresas. De acordo com SILVEIRA (et al., 2002), o mercado tecnológico apresenta grande influencia na distribuição dos produtos de turismo e hospitalidade. A principal função deste mercado é facilitar o processo de compra, venda e a troca de informações. O desenvolvimento da tecnologia dentro do turismo possibilita a criação de estratégias que proporcionam facilidades, tanto para os turistas, quanto para as empresas deste setor.

A TI é um fator importante para a competitividade das empresas nesta era globalizada. Pode-se afirmar que quem não a tem poderá estar fora do mercado, em breve. Atualmente, não se pode imaginar o que seria, por exemplo, dos bancos, das transportadoras aéreas, dos hotéis, das agências de viagens, entre outros, sem a TI.

\subsection{Nova Estrutura de Negócio}

Nesta seção discute-se as mudanças que vêm ocorrendo no segmento do turismo a partir do advento da TI. Além disso, aborda-se o novo papel 
desempenhado pelo consumidor nas transações comerciais da economia digital, e a necessidade das empresas se adaptarem a esse novo cenário.

De acordo com MAYA \& OTERO (2002) a forma como os consumidores eram focados antes do advento da Internet está perdendo sentido, na medida em que o novo cliente da economia on-line é mais bem informado, possui mais opções de escolha e independência de compra. As organizações necessitam, portanto, estabelecer com ele novos vínculos para atingir seus objetivos institucionais.

A Internet dispõe de uma gama de oportunidades de negócios para as organizações que atuam no setor do turismo, principalmente para aquelas que pretendem realizar a distribuição de seus produtos/serviços de forma on-line. Neste sentido, o Comércio Eletrônico (CE) surge como um novo instrumento para agregar valor e vantagem competitiva às empresas do setor do turismo. MARÍN (2004), define CE como a atividade de compra/venda de produtos e serviços suportada por meios eletrônicos.

Segundo MAYA \& OTERO (2002), o negócio eletrônico (e-business) está causando uma revolução que ameaça os fundamentos dos negócios tradicionais, e as empresas que reconhecem a oportunidade que a Internet oferece já começaram a estabelecer sua presença on-line. Para SEYBOLD (2000), um fator crítico no sucesso de um empreendimento on-line consiste na capacidade das empresas em redesenhar os processos organizacionais "de fora para dentro", começando a partir do ponto de vista do cliente.

Diante desta realidade, os profissionais que atuam no setor do turismo devem estar preparados para verificar quais são realmente as necessidades dos clientes. Uma forma de aumentar a probabilidade de venda dos produtos turísticos e a satisfação dos clientes é saber em que grupo cultural eles estão inseridos. Desta forma, será possível oferecer serviços personalizados, de acordo com os gostos de cada consumidor. Para tanto, é necessário aprimorar o fluxo de informações, construindo um banco de dados, onde constem informações sobre o comportamento, a personalidade e as preferências de cada consumidor.

É importante ressaltar, que todos os funcionários que atuam na linha de frente, ou seja, os que têm contato direto com os clientes, devem ter acesso às 
informações contidas em um banco de dados. Muitas vezes, há resistência por parte de alguns funcionários em compartilhar informações. Um fator importante que explica tal atitude é a necessidade que eles têm de assegurar sua posição, justificando, em parte, as comissões obtidas por seu trabalho. É comum, verificar-se agentes de viagens se desligarem de uma agência e levarem consigo todos os processos e informações dos clientes que atendem causando danos para a empresa.

Conforme visto na seção 2.3, a Tl é de fundamental importância para as empresas do setor do turismo, pois essa tecnologia oferece grande potencial de redução de custos, além de possibilitar a ampliação dos seus mercados. Entretanto, algumas empresas estão encontrando dificuldades para ter acesso às inovações tecnológicas.

Segundo TAKAHASHI (2000) uma pesquisa realizada junto às Pequenas e Médias Empresas (PME) paulistas revelou que 27\% dessas empresas tinham acesso à Internet em 1998. Na mesma pesquisa, a maior parte das empresas considerou que o mais importante obstáculo à informatização não estava na área técnica, mas na financeira. A falta de recursos próprios e as dificuldades de acesso ao crédito eram os maiores empecilhos ao fortalecimento das PME. Além disso, as PME enfrentaram outros obstáculos à utilização da rede global, como a falta de percepção das oportunidades oferecidas pelo $\mathrm{CE}$, a incerteza quanto a seus benefícios para o negócio, a falta de produtos adequados e de sistemas integrados para utilização da Internet.

Constata-se, através dos dados apurados nesta pesquisa, que alguns empresários ainda desconhecem os benefícios que a informatização pode trazer para o seu negócio. Este fato representa uma perda de competitividade para essas empresas, tendo em vista que o uso da TI pode gerar reduções significativas de custos, além de facilitar o processo de compra, venda e a troca de informações. A informatização, aliada ao conhecimento dos membros de uma organização, faz a diferença na nova economia.

Para alavancar o desenvolvimento da nova economia no Brasil é necessário acelerar a introdução de novas tecnologias no ambiente empresarial. Além disso, é de fundamental importância promover uma política 
de inclusão digital, preparando os cidadãos para trabalharem com as ferramentas da TI. Essas medidas criam condições para que a economia brasileira possa competir no mercado mundial. Parte-se da premissa que a iniciativa de fomentar o uso das inovações tecnológicas deve partir da esfera pública. O impacto positivo que a "nova economia" pode gerar para o Brasil está atrelado à participação do maior número possível de pessoas, organizações e regiões como usuárias ativas da TI.

\subsection{Vantagem Competitiva para as Agências de Viagens}

Esta seção apresenta a nova realidade enfrentada pelas agências de viagens após o advento da Internet, o surgimento da democratização da informação e a forma pela qual as agências podem agir para continuarem sendo intermediários importantes para os clientes, ou seja, como devem agir as agências de viagens para obterem vantagens competitivas por meio da TI.

De acordo com MAYA \& OTERO (2002), os agentes de viagens levaram, por muito tempo, vantagens nas suas relações comerciais com os consumidores, em virtude do seu poder de acesso à informação. No entanto, o avanço tecnológico e a popularização da Internet proporcionaram ao consumidor final um poder maior de negociação. A partir desse estágio, houve uma mudança nas relações de consumo entre o viajante e o agente de viagens.

Com o advento da Internet, a acessibilidade às informações atingiu desde os agentes de viagens profissionais dos anos 70 e 80 , até os usuários finais nos anos 90. A Internet ativou também as vendas diretas desde o fornecedor até ao cliente final, forçando o reposicionamento dos intermediários tradicionais. As agências de viagens terão que encontrar estratégias para combinar competição das vendas diretas de companhias aéreas e cadeias hoteleiras.

Segundo RENCOMMS (2004) apud (MARÍN, 2004), a democratização da informação eliminou o valor agregado que o controle exclusivo das informações proporcionava aos agentes de viagens, pois qualquer viajante 
passou a acessá-las sem a necessidade de ajuda de intermediários. Essa perda obrigou os agentes de viagens a aderir ao atendimento personalizado.

Para MARÍN (2004), as agências de viagens do século XXI precisam tornar-se autênticas consultoras de viagens, aumentando o valor agregado, e reduzindo seus custos para sobreviver com os novos níveis de receita. Elas precisam conhecer muitos serviços em maior profundidade, ajudar a criar sofisticados pacotes de viagens, solucionar todo tipo de problema dos viajantes e aumentar a produtividade para suportar a queda na rentabilidade.

De acordo com LOPES (1999), a Internet significa um grande desafio para as agências de viagens, elas precisam se reinventar. Precisam deixar de vender somente passagens e quartos de hotel e passar a vender informação, a atuar como verdadeiras consultoras de viagens, agindo em prol do consumidor. As que não entenderem isso estão destinadas a desaparecer.

Da mesma forma salienta DICKMAN (1989) os agentes de viagens não podem se limitar em vender transporte, acomodação e excursões de fornecedores. Eles também devem estar preparados para organizar planos de viagens para clientes e fornecer aconselhamento e informações especializadas sobre o destino.

Para DI SERIO \& MAIA (2004), o real problema das agências de viagens é fazer com que as informações sobre os produtos sejam transmitidas aos clientes de forma adequada. O produto turístico é intangível, não pode ser visto, tocado ou fisicamente inspecionado antes da compra. Isto significa que o consumidor é dependente da informação. Portanto, os agentes de viagens não podem exercer somente a função de vender passagens. Além disso, eles podem oferecer aos consumidores informações sobre os tipos de produtos, datas, localizações, moedas estrangeiras e, baseado nessas informações, dar aconselhamento aos clientes.

Pode-se constatar que os autores têm a mesma visão, no que se refere ao comportamento dos agentes de viagens. Eles são unânimes em afirmar que os agentes que quiserem sobreviver nesta era globalizada precisarão tornar-se consultores de viagens, isto é, intermediários realmente importantes, preparados para dar aconselhamento aos clientes. 
Um fator importante para que as agências de viagens possam ter êxito em seus negócios é a maneira proativa de potencializar suas forças na Internet, aumentando a eficiência e adicionando valor para o cliente. Os intermediários que não agregarem valor aos serviços prestados aos clientes, caso não mudarem, não sobreviverão. O valor agregado pode estar em forma de conhecimento, serviço personalizado e adequação dos serviços para o cliente a cada dia mais sofisticado.

Partindo-se da premissa que o foco principal deve ser agregar valor para o cliente, presume-se que os consultores de viagens devem ter conhecimento especializado e infra-estrutura tecnológica adequada. Segundo MARÍN (2004, p. 70), para que uma agência tenha capacidade de atrair os consumidores até a loja é preciso:

- oferecer as melhores condições a cada cliente;

- personalizar o atendimento a cada cliente;

- atender os seus clientes todos os dias do ano, a qualquer hora;

- facilitar as tarefas administrativas de seu cliente;

- ajudar a conter as despesas administrativas de seu cliente;

- oferecer informações úteis para a tomada de decisões do cliente;

- gerenciar as negociações de seus clientes com fornecedores;

- oferecer maior autonomia aos clientes;

- ajudar as empresas-cliente a oferecer maior valor agregado para seus funcionários;

- converter em clientes os funcionários das empresas-cliente;

- Realizar atividades promocionais;

Pode-se perceber que essas estratégias precedem de um bom sistema de gestão para auxiliar as agências no tratamento dessas informações. Muitas agências procuram superar obstáculos com supostas melhorias no atendimento. No entanto, CARVALHO (2001) apud (MARÍN, 2004) observa que existe um grau de preocupação pequeno com a gestão da informação e que a qualidade do serviço depende excessivamente do conhecimento de cada funcionário. Portanto, pode-se afirmar que quando se trata de competitividade, soluções sujeitas à boa vontade e a simpatia de um funcionário não são mais 
suficientes. É preciso implementar medidas mais bem estruturadas que garantam a sobrevivência das agências de viagens nesta era globalizada.

\subsection{Considerações finais}

Com o advento da Internet e o crescimento do número de internautas, muitas companhias aéreas começaram a fazer reservas e vender seus serviços diretamente ao consumidor final, passando a disputar o mercado das agências de viagens. Neste sentido, a situação das agências de viagens se tornou preocupante, pois além de enfrentarem a concorrência por parte das companhias aéreas, houve diminuição da lucratividade, ocasionada pela redução dos percentuais das comissões de venda.

Outro fator importante é que, atualmente, os consumidores aumentaram os seus padrões de exigências e de expectativas em relação à qualidade dos produtos e serviços prestados. Hoje, as agências de viagens devem agir como consultoras e prover aquilo que o consumidor realmente solicita e não mais o que elas pensam que deve ser oferecido. $O$ atendimento deve ser personalizado.

Dentro desta nova realidade, as agências de viagens devem mudar suas estratégias de ação a fim de estarem aptas a enfrentarem os novos desafios e garantirem a lucratividade. A TI pode auxiliar as agências neste sentido. Ela se destaca hoje, como uma ferramenta fundamental para alavancar os negócios, na medida em que proporciona redução de custos, agilidade e acesso mais direto aos consumidores, entre outros benefícios.

No capítulo 3 serão apresentadas as soluções tecnológicas que estão à disposição das agências de viagens como: a) front -office e CRM, b) backoffice, c) Gestão Integral e ERP, d) comércio eletrônico, e) marketing eletrônico. 


\section{Capítulo 3}

\section{Tecnologia da Informação nas Agências de Viagens}

Neste capítulo são identificadas cinco soluções tecnológicas que estão à disposição das agências de viagens e orienta os agentes de viagens sobre a utilização dessas ferramentas.

\subsection{Soluções Tecnológicas para as Agências de Viagens}

As agências de viagens precisam aproveitar os recursos tecnológicos que a TI pode oferecer. No entanto, deve-se investir na tecnologia mais apropriada à realidade de cada agência. SILVEIRA (et al., 2002, pág. 3), faz a seguinte observação:

A utilização de toda a inovação tecnológica deve ser estudada cuidadosamente e não implantada ou adotada somente porque é bonita ou moderna. A harmonia deve ser buscada entre a estrutura da organização e a arquitetura global do sistema de informações, assim como a linguagem utilizada na empresa deve ser padronizada.

Em muitos casos, o gerente de uma agência de viagens acaba adquirindo um equipamento de $\mathrm{TI}$, impressionado pelos argumentos do vendedor, não consultando um técnico de informática para verificar se aquele equipamento realmente atende as necessidades da agência. O critério a ser seguido na escolha de sistemas deve ser o custo/benefício.

MARIN (2004) identifica cinco soluções tecnológicas a disposição das agências de viagens, no Brasil e no mundo:

- Front-office e CRM 
- Back-office

- Gestão Integral e ERP

- Comércio eletrônico

- Marketing eletrônico

\subsubsection{Front-office e CRM}

Atualmente, com a retenção dos clientes no topo das prioridades, tornou-se importante medir e monitorar a satisfação dos clientes e, em seguida, utilizar essas informações para melhorar continuamente sua satisfação. Para fazer com que isso aconteça é necessário contar com técnicas e ferramentas que nos permitam, primeiramente, identificar quais são os requisitos desejados pelos clientes e, em seguida, medir e monitorar como se pode atender esses requisitos. Desta forma, começaram a surgir sistemas e procedimentos de coleta e análise de informações sobre clientes, como o front-office e o CRM.

O termo inglês front-office pode ser traduzido como frente de loja. De acordo com MARIM (2004, p. 109), o front-office se aplica às agências de viagens para determinar todas as atividades relacionadas com os clientes. Essas atividades podem variar da gestão de vendas e conhecimento das preferências de cada cliente à gestão de reclamações.

A grande variedade e a complexidade das informações a serem tratadas no ponto de venda, e a dificuldade de substituir pessoas por processos mecânicos na assistência aos clientes são fatores que dificultaram a proliferação de sistemas de front-office.

Outro fator que tem servido de justificativa para o adiamento de investimentos em sistemas de maior valor agregado é o baixo nível salarial geralmente praticado nos departamentos de vendas das agências de viagens. Alguns gestores de agências acreditam que é mais vantajoso contratar mão de -obra a baixo custo que investir em tecnologia para melhorar o serviço. Além disso, a oferta de sistemas de front-office em si é bastante reduzida. Existem no mercado poucos produtos que otimizem os processos realizados na linha de frente, observa MARÍN (2004). 
Da mesma forma que o front-office, os CRM também acabaram não se proliferando. Até no momento não existe no Brasil nenhum sistema de CRM dedicado a agências de viagens. Apenas as maiores agência de viagens, como a Flytour (www.flytour.com), e algumas agências virtuais, como a Decolar (www.decolar.com), têm conseguido desenvolver ou implementar soluções comerciais de CRM, integrando inúmeros sistemas isolados e adaptando-se às necessidades do turismo.

Segundo MARÍN (2004, p. 110), os CRM podem ser definidos como conjuntos de estratégias, processos e ferramentas baseados em arquiteturas informáticas, concebidos para recolher, armazenar e explorar informações sobre os clientes com o objetivo de desenvolver relacionamentos produtivos de longo prazo que permitam personalizar o serviço às necessidades de cada um deles.

\subsubsection{Back-office}

O termo inglês back-office, pode ser traduzido como "fundos de loja". De acordo com MARÍM (2004), esse sistema aplica-se às agências de viagens para determinar todas as atividades internas realizadas na empresa. Essas atividades vão desde a operação de pacotes, emissão de bilhetes, envio de documentação, até a administração geral, financeiro, contabilidade e recursos humanos. Pode-se dizer que esses sistemas ajudam a guardar e organizar as informações, controlar as operações, gerenciar o conhecimento e otimizar o fluxo interno de informações.

Neste sistema, o funcionário, em somente uma tela, possui todas as ferramentas integradas podendo utilizar o correio eletrônico, fax, emitir faturas sem a necessidade de acessar vários aplicativos. Este sistema permite a geração de controles e informações tanto administrativas quanto financeiras, estatísticas diárias de vendas em tempo real auxiliando nas decisões.

Pode-se observar que o back-office é um sistema de gestão eficiente, no entanto, a complexidade do setor de turismo, aliada baixa capacidade de investimento das agências de viagens no Brasil, fizeram com que os 
fornecedores não tivessem muito interesse em construir sistemas específicos para essas empresas. Desta forma, as agências foram forçadas a desenvolver seus próprios sistemas de gestão.

\subsubsection{Gestão integral da agência e ERP}

Segundo MARÍN (2004), sistemas de gestão integral de turismo são arquiteturas informáticas que permitem a integração de todas as funções da empresa, com o objetivo de ganhar maior controle sobre as operações necessárias para tomar decisões estratégicas. Através desse sistema é possível eliminar redundâncias, pois independente das funções que desempenham, os usuários passam a olhar para uma única fonte de dados.

Inicialmente esses sistemas foram pensados para a indústria, posteriormente foram adaptados a outros setores, como o de alimentos, o comercial e o de serviços. Os primeiros sistemas integrados fora do turismo foram os sistemas de Planejamento de Recursos Empresariais (ERP). De acordo com INFORMATUR (2003) apud (MARÍM 2004), esses sistemas constituem uma arquitetura de software que facilita o fluxo de informações entre todas as funções dentro de uma companhia, tais como logística, finanças e recursos humanos.

No entanto, embora os fabricantes de ERP tenham adaptado esses sistemas a muitos segmentos, a natureza das agências de viagens tem limitado o interesse desses fabricantes pelo setor. Mesmo assim, segundo INFORMATUR (2003) apud (MARÍM 2004), algumas agências, como a Avipam (www.avipam.com.br), têm realizado investimentos milionários em tecnologia, estimados em mais de 1 milhão de dólares, para adaptar sistemas de ERP convencionais, como o SAP (www.sap.com.br), as suas atividades. 


\subsubsection{Comércio Eletrônico}

De acordo com BISSOLI (1999), antes de a Internet ser utilizada para realização de negócios na área de turismo, os Sistemas Globais de Distribuição (GDS) eram os principais meios eletrônicos para distribuição e comercialização dos serviços. Os GDS são sistemas usados pelas agências de viagens, que possibilitam a realização de transações em tempo real, além de oferecer funções como: informações sobre horários, disponibilidade de serviços, cotação de tarifas de serviços turísticos em todo o mundo, reservas de leitos e assentos, venda e emissão de bilhetes aéreos.

No entanto, cabe ressaltar que, atualmente, os GDS estão cortando incentivos e até retirando alguns equipamentos das agências de viagens. De acordo com MARÍN (2004), isso se deve a redução das margens operativas em toda a cadeia de intermediação e a possibilidade de conflito de interesses entre GDS e agência. Desta forma, os agentes de viagens precisam tomar para si o controle da sua estratégia de negócios, inclusive da estratégia tecnológica.

Neste sentido, a utilização do comércio eletrônico é uma das alternativas disponíveis para as agências de viagens se tornarem independentes dos GDS e obterem vantagem competitiva frente aos seus concorrentes. Entende-se por CE, segundo ALBERTIN (2002) a realização de toda cadeia de valor dos processos de negócio num ambiente eletrônico, através da aplicação intensa das tecnologias de informação, atendendo os objetivos de negócio. Desta forma, o uso do CE implica na integração de todos os processos de negócio da empresa, através de seus sistemas de informação.

Nas agências de viagens, esta modalidade de comércio pode envolver reservas de passagens aéreas, cotações de moedas, cotação de serviços, pagamentos e emissão de documentos para viagem. A utilização do comércio eletrônico possibilita a redução de custos de distribuição, além disso, agiliza os processos de compra/venda.

A capacidade de incluir não só informação codificada, mas também textos formatados, imagens e até mesmo, gravações de áudio e vídeo on demand fez com que muitos produtores e agentes de viagens aderissem ao comércio eletrônico à procura de novos canais de venda e redução de custos. 
Hoje, com o avanço tecnológico, os processos passaram a ser cada vez mais apoiados ou até mesmo substituídos pelos virtuais. No processo virtual, o produto ou serviço existe sob a forma de informação digital, cuja disponibilização pode ser realizada eletronicamente. As agências de viagens virtuais podem ser vistas como uma nova maneira de organização de atividades de negócios. Hoje é possível realizar várias transações on-line, entretanto, ao contrário de muitas empresas do setor turístico, as agências de viagens não costumam ficar on-line, utilizam o site apenas para oferecer informações.

De acordo com MARÍN (2004), on-line é a modalidade de comércio eletrônico que automatiza todo o processo de pesquisa e reserva, acessando bancos de dados em que o produtor cadastra os seus produtos. Já as transações off-line são aquelas nas quais o sistema simplesmente automatiza o processo de solicitação, fazendo-se necessário que um agente opere as reservas manualmente.

No Brasil, os números do turismo on-line ainda são pouco expressivos. Isso se deve em parte a pouca disponibilidade de sites nacionais em turismo. Além disso, são poucos os agentes de viagens que conseguem ter bloqueios que garantam a disponibilidade, e a maior parte dos sites de agências conta apenas com sistemas informativos não transacionais. Ainda mais: a grande maioria dos sites de agências que anunciam "venda on-line" resume sua interatividade em formulários de solicitação enviados por e-mail.

Um dos principais problemas enfrentados por internautas sobre a possibilidade de fazer reservas on-line é a necessidade de contar com um product mix adequado, isto é, diversidade de produtos para o consumidor poder escolher o serviço que mais Ihe agrade. Por este motivo, o consultor de viagens virtual precisa contar com uma grande variedade de produtos para atender as necessidades de seus clientes. 


\subsubsection{Marketing eletrônico}

De acordo com MARÍN (2004), marketing eletrônico é o processo que implica analisar o mercado e promover a venda de serviços on-line. $O$ marketing eletrônico na Internet (e-marketing) apresenta para KOTLER (2000), cinco grandes vantagens em relação ao marketing off-line: a) tanto grandes como pequenas empresas podem enfrentar seus custos; b) não há limite real de espaço para propaganda, em contraste com as mídias tradicionais; c) o acesso e a recuperação das informações são rápidos; d) o site fica disponível para o mundo todo, vinte e quatro horas por dia; e) a compra pode ser feita com privacidade e rapidez.

Em relação ao setor de turismo, MIDDLETON \& CLARKE (2002 p. 339), identificam alguns fatores que colaboram para o surgimento do marketing eletrônico:

- A necessidade de conhecer os perfis dos clientes, para personalizar produtos e obter sua fidelidade;

- Redução de custos de distribuição, para obter vantagens competitivas através dos preços;

- O desenvolvimento da tecnologia de bancos de dados de baixo custo;

- O potencial oferecido pela Internet nas comunicações diretas a partir dos anos de 1990.

De acordo com MARÍN (2004), do ponto de vista da comunicação, as agências de viagens podem realizar campanhas de vendas, de publicidade e ainda gerenciar suas marcas por meio da Internet. As estratégias de promoção eletrônica mais usadas são: website, web tracking, publicidade on-line, newsletters on-line, e-mail e SMS.

\subsubsection{Website}

Website é um conjunto de informação, arquivos e aplicações acessíveis a partir de uma única URL. Para AMOR (2000) apud MAYA \& OTERO (2002), o design do website é muito importante, pois é a primeira impressão que os 
clientes terão da empresa. Entretanto, mais importante ainda em uma página web é o conteúdo, que deve estar atualizado, aumentando, assim, a possibilidade de que os usuários retornem novamente para procurar por mais informações e notícias novas.

O website é uma opção eficaz para promover o marketing global de uma agência de viagens, entretanto, ele deve ser divulgado para que os clientes possam encontrá-lo. As formas mais comuns de se encontrar sites na Web é por meio de sites de busca, como Google (http://www.google.com) ou Yahoo! (http://www.yahoo.com), onde os sites devem ser voluntariamente cadastrados por seus detentores para que se tenha maior garantia da indexação, através de publicidade on-line em outros sites e por mídia tradicional.

\subsubsection{Web Tracking}

Através do web tracking é possível analisar a conduta dos internautas em detalhes. Além de ser importante ter um site atrativo e saber conquistar visitas, é necessário poder avaliar o resultado do site e melhorar constantemente sua arquitetura, assim como a estrutura e o teor das informações nele contidas. De acordo com MARíN (2004), os sistemas de controle de tráfego podem ajudar a controlar o comportamento de visitantes para avaliar a eficácia de sites em relação aos objetivos estratégicos marcados para esta mídia.

\subsubsection{Publicidade on-line}

A publicidade on-line é utilizada para fortalecer uma marca na Internet ou divulgar uma empresa ou produto em outros sites e portais, oferecendo a possibilidade de desviar o cliente para o site do anunciante. As formas de publicidade on-line são muitas, de acordo com CARVALHO (2004, p. 66) as mais comuns são: 
- "banners": imagens animadas ou não, geralmente retangulares, posicionadas no topo, no rodapé ou nas laterais de sítios visitados;

- "popups": são pequenas janelas do navegador que "pulam" (da expressão inglesa pop-up) sobre a janela onde ocorre a navegação principal;

- "links patrocinados", como os "banners", são anúncios promovendo a empresa ou produto do anunciante. Difere destes basicamente por não serem constituídos por imagens, mas apenas por texto;

- "tickers" são como "banners", mas possuem forma mais trabalhada (contornos) e se movimentam pela tela;

- bloqueios de estrada": são páginas intermediárias, exibidas entre um sítio e outro quando realizado um clique sobre um link.

Um fator importante a ser ressaltado em relação à publicidade on-line é que esta pode ser exibida tanto aleatoriamente, como pode ser direcionada por sites e portais que detém o perfil de seus usuários - de acordo com os interesses de quem está navegando, ou ainda, pode ser exibida numa lista paralela ao resultado de uma busca.

Algumas formas de publicidade são freqüentemente taxadas pelos usuários de inconvenientes, como "popups", "tickers" ou "bloqueios de estrada". Muitos profissionais de marketing utilizam os recurso da TI de forma abusiva, ocasionando um assédio aos clientes, que acabam ficando irritados. O ideal seria pedir permissão aos clientes antes de se usar essas estratégias. Quando o consumidor concorda em prestar atenção às mensagens enviadas, torna-se mais fácil informá-lo sobre os produtos ou serviços oferecidos pela empresa.

\subsubsection{Newsletters on-line}

Através dessa modalidade eletrônica é possível manter um contato regular com os clientes, potencializar o estabelecimento de uma relação, assim como um elevado índice de reconhecimento da marca. Segundo MARíN (2004), este tipo de publicação eletrônica permite que a agência envie 
informações multimídia sobre a empresa e suas atividades a um grupo de assinantes, constituída por públicos diversos. Ao invés de enviar correspondência física aos clientes, envia-se mensagens multimídia ou textuais informando-os sobre novos produtos, ofertas, promoções e cartões de aniversário. Habitualmente incluem links para o site da agência.

O "newsletters on-line" é realizado a partir de uma lista de clientes que concordam previamente (ao realizar um cadastro ou preencher um formulário) em receber informações sobre determinados assuntos de seu interesse, diferentemente do "Span", que é enviado à uma lista de e-mails sem o consentimento do destinatário, como publicidade indesejada. Geralmente são utilizadas para transmitir informações de setores específicos.

\subsubsection{E-mail e SMS}

Dentre as diversas técnicas utilizadas na implementação de marketing eletrônico, o e-mail é considerado como uma das mais poderosas, dadas as suas elevadas potencialidades e o seu custo reduzido.

É importante construir uma base de dados segmentada e desenvolver mensagens que atinjam a cada segmento especifico. Por exemplo: uma agência de viagem pode enviar promoções e anúncios de turismo cultural para os clientes adeptos a esse segmento. A segmentação da base de dados pode ser construída a partir de cada contato com o cliente.

Embora o e-mail e o $\mathrm{SMS}^{3}$ sejam considerados a forma mais eficaz de promover vendas, algumas agências de viagens vêm abusando dessas estratégias de marketing. De uma forma resumida, ao se fazer uma campanha de marketing através de e-mail, deve-se procurar respeitar as seguintes regras:

1. Enviar e-mail apenas a quem optou em recebê-los;

2. Respeitar sempre os pedidos de pessoas que não pretendem continuar a receber os e-mails;

\footnotetext{
${ }^{3}$ SMS - Do inglês short message service, são mensagens curtas de texto, enviadas a partir de dispositivos móveis, tais como telefones celulares.
} 
3. Permitir que os utilizadores especifiquem as suas preferências sobre o tipo de informações que desejam receber e com que freqüência;

4. Ser criativo e enviar sempre algo de valor juntamente com a sua mensagem;

5. Não vender as listas de e-mail;

6. Responder rapidamente às perguntas formuladas pelos clientes via e-mail;

7. Não utilizar listas de e-mail alugadas, pois pode produzir spam e criar uma péssima imagem junto aos receptores dos e-mails;

8. Lembrar sempre do efeito de rede, na Internet o que se propaga mais depressa são as más notícias.

Ao se elaborar uma mensagem é importante chamar a atenção dos clientes nas primeiras frases. No final da mensagem é essencial fazer uma identificação completa (nome da empresa, endereço, telefone, fax e URL) e dar ao receptor a oportunidade de declinar a recepção de futuras mensagens. Deve-se ter cuidado com a inserção de figuras no meio do texto, pois nem todos os softwares de e-mail estão preparados para ler figuras.

\subsection{Considerações Finais}

Pode-se constatar, pelo capítulo 3 , que o comércio eletrônico e o marketing eletrônico são soluções de informática que estão se tornando cada vez mais acessíveis aos agentes de viagens.

No Brasil, a proliferação de sistemas de gestão como: front-office ${ }^{4}$, backoffice $^{5}$, gestão integral ${ }^{6}$ e $\mathrm{ERP}^{7}$ é reduzida. Isso ocorre em virtude do custo

\footnotetext{
${ }^{4}$ Front-office - esse termo pode ser traduzido como "frente de loja". O front-office pode aumentar as oportunidades de faturamento e criar condições para melhorar o relacionamento com os clientes.

${ }^{5}$ Back-office - esse termo pode ser traduzido com "fundos de loja". Esse sistema aplica-se a realização de todas as atividades internas de uma empresa.
} 
desses sistemas ser elevado, e de não existirem no mercado, sistemas desta natureza específicos para o setor de turismo, pois os fornecedores de informática preferem canalizar seus recursos no desenvolvimento de sistemas para setores mais rentáveis do que o setor de turismo.

No capítulo 4 será realizada a análise de dados, onde será possível verificar os relatos de cada agência de viagem pesquisada, em relação à utilização da TI em seus negócios.

${ }^{6}$ Gestão integral - esse sistema possibilita a integração de todas as funções da empresa, com a finalidade de se obter maior controle sobre as operações necessárias para tomar decisões estratégicas.

${ }^{7}$ ERP - Do inglês Enterprice Resourse Planning. Esse sistema facilita o fluxo de informação entre todas as funções dentro de uma companhia. 


\section{Capítulo 4 \\ Análise de Dados}

Neste capítulo será realizada a análise de dados, que consiste de uma descrição comparativa e analise da pesquisa realizada, em cada empresa em relação à utilização da TI em seus negócios. Esta análise busca identificar e comparar as diferenças e semelhanças entre a percepção de cada agência de viagem estudada em relação às perspectivas das ferramentas da $\mathrm{TI}$ na realização de negócios turísticos.

De acordo com YIN (1994) a coleta de dados em um estudo de caso deve envolver um grau de discrição por parte do pesquisador, o qual deve possuir características e habilidades certas para realizar esse tipo de pesquisa.

\subsection{Método adotado para realizar a pesquisa}

Procurou-se fazer a pesquisa levando em conta as recomendações de YIN (1994), de forma objetiva e imparcial. As perguntas do questionário foram elaboradas em consonância com o problema, os objetivos e hipóteses do trabalho. RICHARDSON (1999) define o questionário como a técnica de pesquisa que cumpre as funções de descrever as características e medir determinadas variáveis de um grupo social, e considera que todo aspecto incluído no questionário constitui uma hipótese, devendo, portanto, ser possível de defender.

O questionário foi construído tendo como finalidade a busca de informações que sinalizassem o comportamento das agências de viagens em 
relação à utilização $\mathrm{TI}$ em seus negócios. Procurou-se entrevistar os proprietários e gerentes das agências de viagens. Cabe ressaltar, que não houve exposição dos entrevistados e das empresas estudadas no trabalho. As agências de viagens não foram identificadas na pesquisa, tendo sido arroladas como Empresa A, Empresa B e assim por diante. A pesquisa foi realizada no mês de fevereiro de 2005.

A amostra da pesquisa corresponde a 20 agências de viagens que atuam no DF. Essa amostra representa $20 \%$ do total das agências de viagens. A relação dessas empresas foi obtida por meio do site da ABAV e a sua escolha foi realizada por sorteio aleatório, conforme explicado na metodologia. As perguntas que foram aplicadas junto às agências encontram-se no apêndice I. A entrevista foi realizada por meio de e-mail, visitas pessoais e telefone.

Em princípio, optou-se por aplicar os questionários somente por e-mail, no entanto, como houve uma baixa taxa de devolução, decidiu-se fazer visitas pessoais. Como não houve tempo hábil para visitar todas as agências da amostra, então se tornou necessário aplicar alguns questionários por telefone.

A seguir são apresentadas as habilidades do pesquisador recomendadas por YIN, 1994:

- Ter natureza inquisitiva;

- Saber formular perguntas inteligentes e interpretar as respostas;

- Ser bom ouvinte, registrando habilidades, sem fixar pré-concepções, valores, juízo, ou parcialidade;

- Ter habilidade de se ausentar da situação e manter a objetividade;

- Ter conhecimento completo do assunto em questão e assuntos relacionados ao estudo;

- Ter habilidade de se adaptar e ser flexível;

- Ter atenção aguda para detalhes;

- Ter astúcia, critério, personalidade sociável e refletiva;

- Ter boas habilidades analíticas, com a habilidade de acumular, reduzir, e prefixar grandes volumes de dados qualitativos preservando seu significado;

- Ter a habilidade de comunicar bem, tanto por escrito quanto oralmente. 


\section{2 Histórico do funcionamento das agências de viagens}

O quadro 4.1 apresenta os aspectos relacionados ao histórico de funcionamento, ao tamanho e a decisão de conexão à Internet das agências que compõem a amostra da pesquisa.

\section{Quadro 4.1}

Histórico de funcionamento das agências de viagens

\begin{tabular}{|c|c|c|c|}
\hline Empresa & $\begin{array}{l}\text { Ano de início } \\
\text { das atividades }\end{array}$ & $\begin{array}{l}\text { Número de } \\
\text { funcionários }\end{array}$ & $\begin{array}{c}\text { Ano em que a } \\
\text { empresas } \\
\text { conectou-se à } \\
\text { internet }\end{array}$ \\
\hline$A$ & 1998 & 3 & 1998 \\
\hline$B$ & 1995 & 6 & 1995 \\
\hline C & 2002 & 12 & 2002 \\
\hline $\mathrm{D}$ & 1987 & 2 & 1995 \\
\hline$E$ & 1986 & 7 & 2000 \\
\hline $\mathrm{F}$ & 2001 & 12 & 2001 \\
\hline $\mathrm{G}$ & 1996 & 10 & 1996 \\
\hline $\mathrm{H}$ & 2001 & 3 & 2001 \\
\hline I & 1979 & 7 & 1995 \\
\hline $\mathrm{J}$ & 1977 & 20 & 1992 \\
\hline $\mathrm{L}$ & 2002 & 3 & 2002 \\
\hline$M$ & 1991 & 2 & 1997 \\
\hline $\mathrm{N}$ & 1966 & 8 & 1999 \\
\hline $\mathrm{O}$ & 1987 & 9 & 2002 \\
\hline$P$ & 1994 & 1 & 2001 \\
\hline $\mathrm{Q}$ & 2003 & 7 & 2003 \\
\hline $\mathrm{R}$ & 1995 & 3 & 2000 \\
\hline $\mathrm{S}$ & 2003 & 2 & 2003 \\
\hline $\mathrm{T}$ & 2003 & 8 & 2003 \\
\hline$U$ & 1994 & 13 & 1999 \\
\hline Média & 1993 & 6.9 & 1999 \\
\hline
\end{tabular}


No quadro 4.1, a primeira coluna mostra as 20 agências entrevistadas $^{8}$. A segunda coluna apresenta o ano em que essas agências iniciaram suas atividades. Na terceira coluna observa-se o número de funcionários de cada uma dessas agências e na parte final da tabela são apresentadas informações relativas ao acesso à Internet. A análise desses dados encontra-se na próxima seção.

\subsection{Análise}

De acordo com o quadro 4.1, nota-se que, em média, essas agências iniciaram suas operações em 1993, estando a agência mais antiga operando desde 1966 e as mais recentes datam do ano de 2003.

Ainda de acordo com o quadro 4.1, pode-se observar que as agências de viagens são de pequeno porte e operam com poucos funcionários, em média 6,9. O gráfico 4.1 ressalta essa conclusão.

\section{Gráfico 4.1}

\section{Quantidade de funcionários nas agências de viagem}

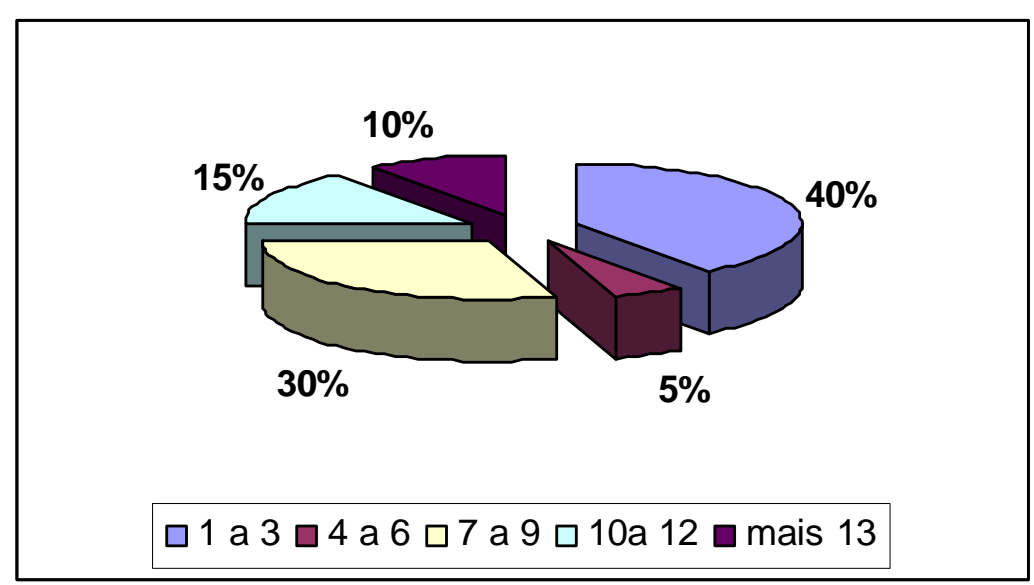

Observando o gráfico 4.1, pode-se dizer que 40\% das agências têm até 3 funcionários, $5 \%$ de 4 a 6 ,30\% de 7 a 9, 15\% de 10 a 12 e 10\% possui mais de 13 funcionários. Esses percentuais mostram que de fato as agências são de pequeno porte, sendo que $75 \%$ delas possuem menos de 10 funcionários.

\footnotetext{
${ }^{8}$ Os nomes foram substituídos por letras para fins de sigilo.
} 
Além das agências serem pouco intensivas no uso de mão de obra, o que pode ser um atributo natural, o baixo número de funcionários pode se dever, em parte, ao uso da $\mathrm{TI}$, que permitiu que as tarefas fossem desempenhadas com maior rapidez, podendo ter levado à redução do número de funcionários para controlar as operações da agência.

No que concerne ao acesso à Internet, a última coluna evidência que o ano de 1999 é a média em que essas agências se conectaram a Internet e não existe uma grande dispersão em torno desta média. Antes de se obter os resultados da pesquisa, supunha-se que menos de $86,65 \%$ das agências de viagens tinham acesso à Internet. No entanto, a pesquisa revelou que atualmente, 100\% das agências entrevistadas têm acesso à Internet. Um aspecto importante a ser observado no quadro 4.1 é que as empresas mais recentes, fundadas a partir de 1996, já iniciaram suas atividades utilizando à Internet. Este fato evidencia que, nesta era globalizada, a Internet é um canal de negócios indispensável para a gestão eficiente das agências de viagens.

\subsection{Utilização das ferramentas da TI pelas agências de viagens}

Pelos estudos realizados até o momento, pode-se constatar que no Brasil há uma proliferação reduzida dos sistemas de gestão como front-office e CRM, back-office, gestão integral e ERP. Isso se deve, em parte, ao fato de que não existem sistemas dessa natureza específicos ao setor do turismo. Além disso, o custo desses sistemas é elevado.

Como apontado por MARÍN (2004), o reduzido tamanho das agências de viagens (quando comparadas a empresas de outros setores), vem restringindo a atratividade do setor para os fornecedores de sistemas de gestão, que preferem canalizar seus recursos no desenvolvimento de sistemas para setores mais rentáveis, como o bancário, o industrial e o químico.

Neste sentido, optou-se por analisar de que forma as agências de viagens estão se comportando em relação à $\mathrm{TI}$, dando ênfase ao comércio eletrônico e marketing eletrônico, tendo em vista que essas são soluções de 
informática que estão mais acessíveis aos agentes de viagens. Procurou-se verificar de que forma as agências estão utilizando a TI nos seus negócios através dos seguintes indicadores: conexão à Internet, sites cadastrados em sistemas de busca, uso de estratégias de promoção eletrônica de marketing, treinamento de funcionários e fidelização de clientes.

\subsection{Utilização das estratégias de promoção eletrônica de marketing pelas agências de viagens}

O quadro 4.2 apresenta as estratégias de promoção eletrônica de marketing mais utilizadas pelas agências de viagens de acordo com MARíN (2004). Essas estratégias compreendem: website, web tracking, publicidade on-line e e-mail e SMS.

Quadro 4.2

Estratégias de promoção eletrônica de marketing utilizadas pelas agências de viagens

\begin{tabular}{|c|c|c|c|c|c|}
\hline Empresa & Website & $\begin{array}{c}\text { Web } \\
\text { tracking }\end{array}$ & $\begin{array}{l}\text { Publicidade } \\
\text { on-line }\end{array}$ & $\begin{array}{c}\text { Newsleter } \\
\text { on-line }\end{array}$ & $\begin{array}{c}\text { E-mail e } \\
\text { SMS }\end{array}$ \\
\hline $\mathrm{A}$ & $X$ & & & & $X$ \\
\hline B & & & & $X$ & $X$ \\
\hline $\mathrm{C}$ & $X$ & & & $x$ & $x$ \\
\hline $\mathrm{D}$ & & & & & $X$ \\
\hline $\mathrm{E}$ & $X$ & & & $X$ & $X$ \\
\hline$F$ & $\mathrm{X}$ & & $X$ & $X$ & $\mathrm{X}$ \\
\hline$G$ & $\mathrm{X}$ & & & $\mathrm{X}$ & $X$ \\
\hline $\mathrm{H}$ & & & & & $X$ \\
\hline I & $X$ & $X$ & & $X$ & $X$ \\
\hline $\mathrm{J}$ & $X$ & & & $X$ & $X$ \\
\hline L & & & & & $X$ \\
\hline$M$ & & & & $\bar{X}$ & $X$ \\
\hline $\mathrm{N}$ & $X$ & & & & $X$ \\
\hline $\mathrm{O}$ & & & & $X$ & $X$ \\
\hline$P$ & & & & $X$ & $X$ \\
\hline $\mathrm{Q}$ & & & & & $X$ \\
\hline $\mathrm{R}$ & $X$ & & & $X$ & $X$ \\
\hline $\mathrm{S}$ & & & & & $X$ \\
\hline $\mathrm{T}$ & $X$ & & $X$ & $X$ & $X$ \\
\hline$U$ & $X$ & & $X$ & & $x$ \\
\hline
\end{tabular}




\section{Gráfico 4.2}

\section{Uso das ferramentas de TI pelas agências de viagens}

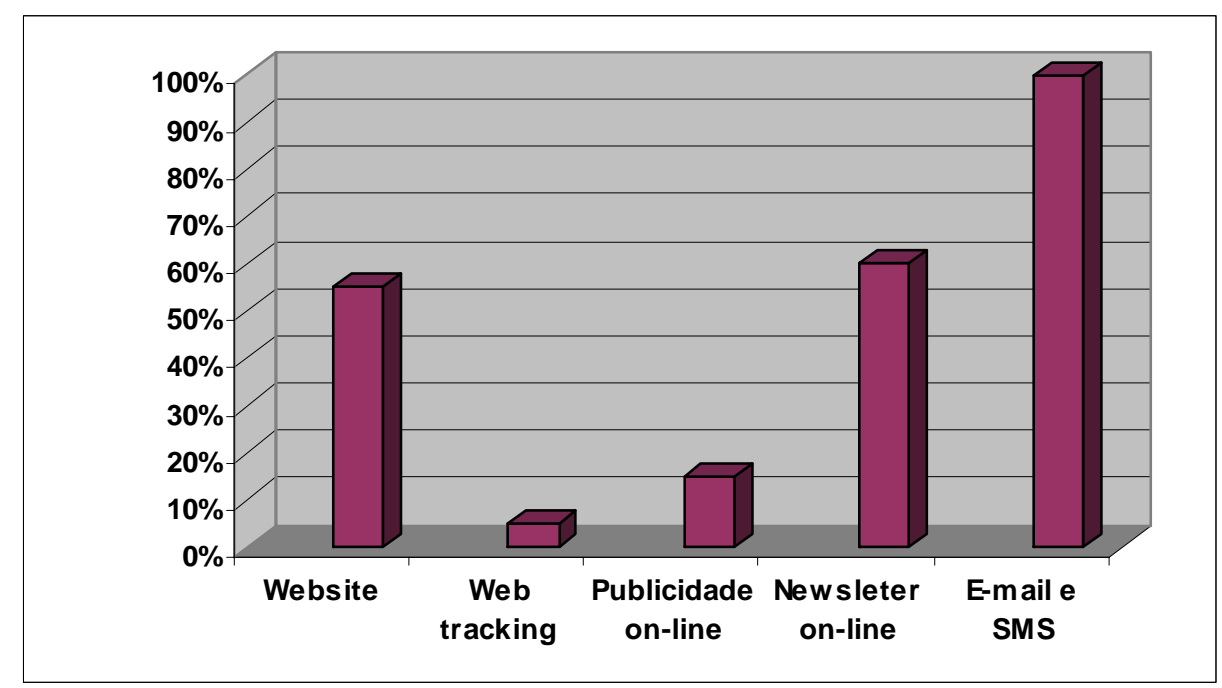

Das vinte agências de viagens entrevistadas, observou-se que onze possuem site, um percentual de 55\%. O site de três agências, 15\%, está em construção. A homepage de nove agências, ou seja, 45\% está inserida em sites de buscas. Somente três agências, 15\%, possuem banners e links em sites institucionais.

Um aspecto importante a ser considerado é o fato de que do total das agências que possuem site, apenas duas, 10\%, realizam vendas on-line. Essas empresas automatizaram todo o processo de pesquisa e reserva e cadastraram seus produtos no site. Essa modalidade de comércio eletrônico permite que o cliente realize todas as transações de forma on-line, inclusive os pagamentos, que são realizados através de cartão de crédito.

Vale ressaltar que, apesar da comodidade oferecida por essa modalidade, a maior parte das vendas das empresas mencionadas anteriormente é realizada de maneira tradicional. Segundo um dos entrevistados, isso se deve, em parte, à cultura do povo brasileiro que, ainda é baseada no contato pessoal e não tendo absorvido as novas tecnologias. Como exemplo, foi citado o caso de clientes que preferem usar o telefone, ou irem pessoalmente à agência, ao invés de utilizarem o correio eletrônico para solicitar reservas de hotéis e passagens aéreas. Outro fator que inibe a realização desta modalidade reside na questão de segurança. Os usuários questionam a segurança no uso de cartão de crédito na Internet. 
As demais agências que possuem site não realizam vendas on-line. Os sites dessas empresas contam apenas com sistemas informativos não transacionais. A grande parte dos sites de agências que anunciam "venda on-line" são sites informativos, resumem sua "interatividade" em formulários de solicitação enviados por e-mail.

Pode-se observar no quadro 4.2 e gráfico 4.2, que a utilização de e-mail é comum a todas as agências de viagens. O web tracking, sistema que analisa em detalhes a conduta dos internautas, é utilizado somente por uma empresa, (5\%). A publicidade on-line, que consiste na aplicação de banners interativos, a fim de atrair tráfego proveniente de outras páginas, é utilizada por três empresas, (15)\% . A newsletters on-line, modalidade de publicação eletrônica que permite o envio de informações multimídia sobre a empresa e suas atividades a uma audiência de assinantes, é utilizada por doze agências de viagens, ou seja, $60 \%$.

Quando perguntado às agências de viagens se existiam obstáculos para implementação das novas tecnologias, surgiram quatro respostas que estão apresentadas no quadro 4.3 e gráfico 4.3.

Quadro 4.3

Obstáculos para implementação de novas tecnologias

\begin{tabular}{|l|l|}
\hline \multicolumn{1}{|c|}{ Respostas } & \multicolumn{1}{c|}{ Empresas } \\
\hline Não existem obstáculos & $\mathrm{C}-\mathrm{E}-\mathrm{G}-\mathrm{I}-\mathrm{Q}-\mathrm{T}-\mathrm{U}$ \\
\hline Custos elevados & $\mathrm{A}-\mathrm{B}-\mathrm{H}-\mathrm{J}-\mathrm{L}-\mathrm{M}-\mathrm{N}-\mathrm{O}-\mathrm{P}-\mathrm{R}$ \\
\hline Questões burocráticas & $\mathrm{F}$ \\
\hline $\begin{array}{l}\text { Dificuldades para conectar as ferramentas } \\
\text { da TI com todas as companhias aéreas. }\end{array}$ & $\mathrm{D}-\mathrm{S}$ \\
\hline
\end{tabular}




\section{Gráfico 4.3}

\section{Obstáculos para implementação das novas tecnologias}

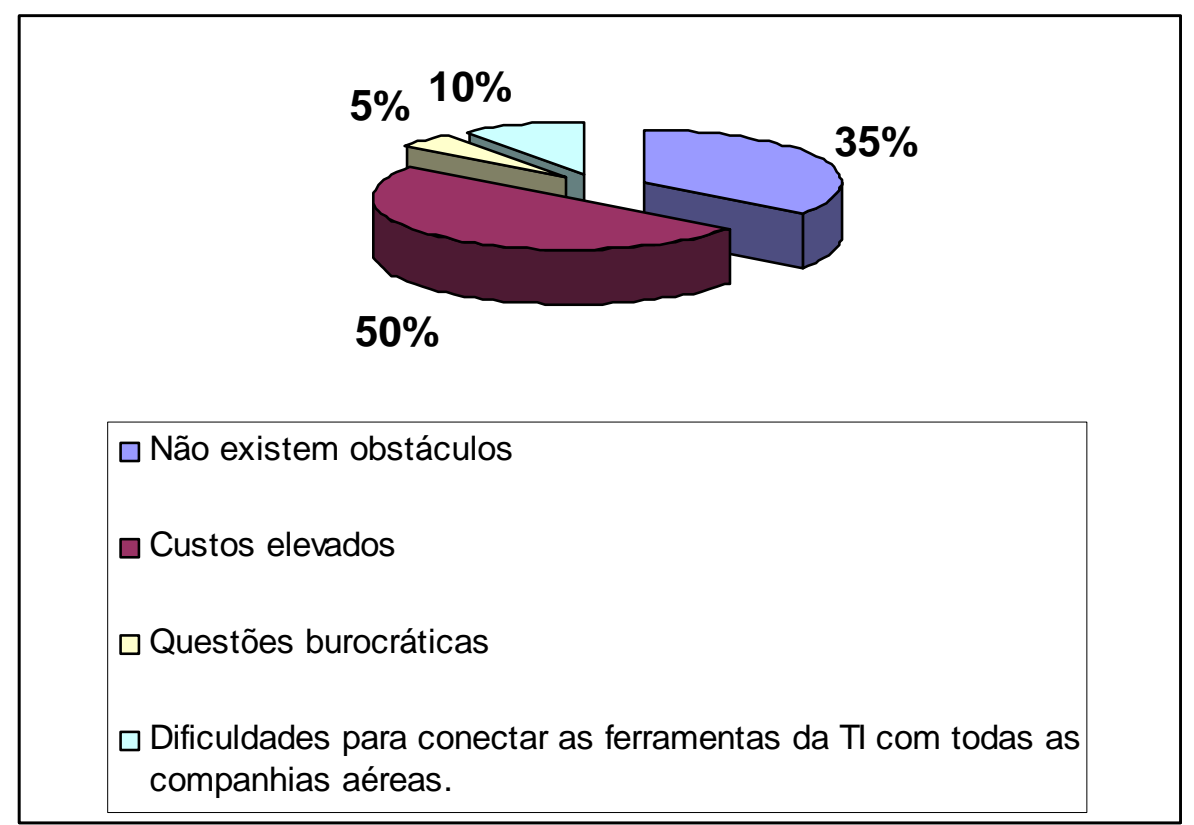

Pode-se observar no quadro 4.3 e no gráfico 4.3, que para sete agências de viagens, (35\%) não existem obstáculos para implementação de novas tecnologias. Na opinião de dez agências de viagens, (50\%) as dificuldades para implementar novas tecnologias residem na questão dos custos que são elevados. Uma agência (5\%) apontou questões burocráticas como o maior obstáculo. Um obstáculo importante a ser observado, mencionado por duas agências, (10\%) é a dificuldade de conectar as ferramentas da TI com todas as companhias aéreas, pois cada companhia aérea possui um programa diferente.

Na opinião da agência $P$, os custos para implementar novas tecnologias são elevados porque existe um monopólio nesta área de informática. Além disso, a falta de conhecimentos técnicos em TI por parte da maioria dos agentes de viagens gera abusos por parte de alguns técnicos de informática.

Quando perguntado sobre o meio utilizado pelas agências para estarem sempre atualizadas em termos de inovações tecnológicas, observou-se as respostas relacionadas no quadro 4.4 . 
Quadro 4.4

Meios utilizados para se obter conhecimentos sobre inovações tecnológicas

\begin{tabular}{|c|c|}
\hline Empresas & $\begin{array}{l}\text { Meios utilizados para se obter conhecimentos sobre inovações } \\
\text { tecnológicas }\end{array}$ \\
\hline A & Internet \\
\hline B & A agência consulta um técnico de informática \\
\hline $\mathrm{C}$ & A agência contratou um técnico de informática \\
\hline $\mathrm{D}$ & ABAV \\
\hline$E$ & Internet \\
\hline $\mathrm{F}$ & $\begin{array}{l}\text { A agência possui um setor de manketing que estuda as tendências do } \\
\text { mercado }\end{array}$ \\
\hline G & $\begin{array}{l}\text { Revistas de informática, jornais. Além disso, a agência contratou um técnico } \\
\text { de informática. }\end{array}$ \\
\hline $\mathrm{H}$ & Não existe um meio específico \\
\hline I & Companhias aéreas, operadoras e fornecedores \\
\hline $\mathrm{J}$ & A agência contratou um técnico de informática \\
\hline L & Não existe um meio específico \\
\hline M & Internet \\
\hline $\mathrm{N}$ & ABAV \\
\hline $\mathrm{O}$ & Companhias aéreas \\
\hline $\mathrm{P}$ & Internet \\
\hline $\mathrm{Q}$ & Internet \\
\hline $\mathrm{R}$ & A agência contratou um técnico \\
\hline $\mathrm{S}$ & Internet, palestras \\
\hline $\mathrm{T}$ & Pesquisa de mercado \\
\hline$U$ & Internet \\
\hline
\end{tabular}

Pode-se observar no quadro 4.4 que a forma mais utilizada pelas agências para se manterem informadas em relação às inovações tecnológicas é através da Internet. O técnico de informática aparece como a segunda opção mais utilizada. As empresas H e L não utilizam um meio específico para isso. 


\subsection{Perfil dos profissionais que atuam nas agências de viagens.}

Em termos de capacitação tecnológica, quando perguntado aos entrevistados se os profissionais que atuam nas agências de viagens estão capacitados para trabalhar com as ferramentas da TI, treze responderam que sim. No entanto, sete agências responderam que nem todos os profissionais que atuam neste setor dominam a tecnologia e muitas pessoas encontram dificuldades neste sentido.

No que se refere ao treinamento de mão-de-obra, pode-se observar que este é um ponto valorizado pela maior parte das agências de viagens pesquisadas. Quando perguntado aos entrevistados se os funcionários da agência recebiam treinamento, dezesseis responderam que sim, e quatro alegaram que não. A maioria dos funcionários que não recebe treinamento aprende a trabalhar com os funcionários mais experientes da empresa.

O ideal seria que todos os funcionários recebessem um treinamento padrão. Quando o aprendizado fica a cargo dos funcionários mais experientes da agência, muitas vezes, os novatos acabam aprendendo a trabalhar sozinhos. Isso ocorre porque os funcionários são comissionados e não querem despender muito tempo ensinando os novos funcionários. Desta forma, cada funcionário acaba desenvolvendo sua própria forma de trabalhar, que pode variar em função de uma série de variáveis. Com isso, os profissionais, em geral, acabam não conseguindo aproveitar integralmente as ferramentas de TI.

No que se refere ao comportamento dos agentes de viagens, pode-se constatar no capítulo 3 que aqueles que almejarem sobreviver nesta era globalizada precisarão tornar-se verdadeiros consultores de viagens, isto é, intermediários realmente importantes, preparados para dar aconselhamento aos clientes. No entanto, percebe-se que nem todos os agentes de viagens se enquadram neste perfil. $\mathrm{Na}$ opinião de treze agências entrevistadas, os profissionais que atuam neste setor estão preparados para organizar planos de viagens para os clientes e oferecer aconselhamento e informações especializadas sobre os destinos que vendem. Na visão de sete agências, os agentes de viagens, em geral, não apresentam perfil de consultores, agem apenas como vendedores de passagens. 
Um comentário que chamou a atenção, feito por um agente que possui vinte anos de experiência no setor, é que a qualidade dos serviços prestados nas agências de viagens, em geral, ao invés de estar melhorando a cada dia que passa, está decaindo. $\mathrm{Na}$ opinião deste agente, isso se deve ao fato de algumas agências estarem contratando mão-de-obra a baixos custos.

\subsection{A Tecnologia da Informação e a fidelização dos clientes}

Em um mercado altamente competitivo, as agências de viagens deparam-se com o desafio de empregar a tecnologia para incrementar a fidelidade dos clientes. Essa ferramenta é importante também neste sentido, pois pode auxiliar o processo de armazenamento e controle das informações. Pode-se definir fidelização de clientes como um conjunto de estratégias que conquistam um relacionamento duradouro.

Segundo TOMELIN (2001), para conquistar a lealdade do cliente é necessário:

a) fazer uso da tecnologia da informação e da comunicação em favor da aproximação cliente/agência de viagens e turismo/agente de viagens;

b) prezar pela satisfação do cliente;

c) transmitir um sentimento de responsabilidade para com o cliente no que se refere ao planejamento da viagem e no feedback da viagem;

d) gerenciar o relacionamento com o cliente;

e) ser flexível a mudanças e resgatar a essência do perfil de consultor;

De acordo com CABRINO (2002), o diferencial competitivo de uma empresa reside na criação de um banco de dados, onde possam ser armazenadas todas as informações imprescindíveis dos clientes. Através do conhecimento dos hábitos e costumes dos clientes é possível antever-se a qualquer ação, surpreendendo e fazendo-se presente em seu cotidiano. Informações históricas são de grande valia, pois tornam a comercialização mais personalizada, mais próxima e informal.

Quando abordada a questão sobre as ações para assegurar a fidelização da clientela, obteve-se as respostas relatadas no quadro 4.5. 


\section{Quadro 4.5}

\section{Fidelização de clientes}

\begin{tabular}{|c|c|}
\hline Empresa & Estratégias utilizadas para fidelização de clientes \\
\hline A & Cartão fidelidade \\
\hline B & $\begin{array}{l}\text { A agência possui um setor de marketing. Os clientes são visitados com } \\
\text { freqüência e recebem newsletters on-line. }\end{array}$ \\
\hline C & $\begin{array}{l}\text { A agência possui um cadastro com informações sobre o perfil dos clientes, o que } \\
\text { permite oferecer um atendimento personalizado, com descontos personalizados. }\end{array}$ \\
\hline $\mathrm{D}$ & A agência não possui um método para fidelizar os clientes \\
\hline $\mathrm{E}$ & Atendimento personalizado \\
\hline $\mathrm{F}$ & A agência não possui um método para fidelizar os clientes \\
\hline G & $\begin{array}{l}\text { A agência sempre dá um feedback para o cliente. Além disso, possui um } \\
\text { cadastro onde constam as datas de aniversário para envio de cartões por e-mail. }\end{array}$ \\
\hline $\mathrm{H}$ & Bom atendimento \\
\hline I & $\begin{array}{l}\text { Bom atendimento. A agência possui um cadastro onde constam as } \\
\text { peculiaridades dos clientes e envia informações sobre pacotes e promoções de } \\
\text { acordo com o padrão de consumo de cada um. }\end{array}$ \\
\hline $\mathrm{J}$ & A agência possui um cadastro de clientes e sempre mantém contato com eles. \\
\hline $\mathrm{L}$ & A agência não possui um método para fidelizar os clientes. \\
\hline M & Mala direta e visitas aos clientes. \\
\hline $\mathrm{N}$ & A agência não possui um método para fidelizar os clientes \\
\hline $\mathrm{O}$ & $\begin{array}{l}\text { Bom atendimento. A agência presta um serviço de assessoria de viagens, isto é, } \\
\text { procura resolver os problemas que eventualmente ocorram durante a viagem. }\end{array}$ \\
\hline$P$ & Envio de cartões de aniversário e contato permanente com os clientes \\
\hline Q & Pós-viagem e bom atendimento \\
\hline $\mathrm{R}$ & Mala direta \\
\hline$S$ & $\begin{array}{l}\text { Bom atendimento, agilidade. Os funcionários estão preparados para transmitir } \\
\text { informações seguras sobre os destinos turísticos que vendem. }\end{array}$ \\
\hline$T$ & Cartão fidelidade \\
\hline $\mathrm{U}$ & A agência não possui um método para fidelizar os clientes \\
\hline
\end{tabular}

Pode-se observar que cinco agências, (5\%) não possuem uma estratégia para fidelizar os clientes. Duas agências (10\%) procuram fidelizar a clientela através do cartão fidelidade. É possível verificar no quadro 4.5 que o atendimento personalizado é o que prevalece, em termos de fidelização dos 
clientes. O conhecimento dos clientes, por parte das agências de viagens, permite que haja um acerto maior na oferta de serviços.

A tecnologia e o atendimento ao cliente estão cada vez mais interrelacionados nesta era da informação. O sistema de informação nas mãos de pessoas hábeis e conhecedoras pode mudar totalmente o ambiente de vendas.

\subsection{Considerações Finais}

Pode-se observar neste capítulo, que as ferramentas de TI são utilizadas de uma forma diferenciada pelas agências de viagens pesquisadas. A maior parte dessas empresas poderia utilizar os recursos que a TI disponibiliza de forma mais intensiva, a fim de se atingir um padrão eficiente de uso. Desta forma, seria possível aumentar a lucratividade e garantir a sobrevivência das agências de viagens a longo prazo. 


\section{Capítulo 5 Conclusão}

O mundo está passando por um momento de grandes transformações. As facilidades proporcionadas pelas inovações tecnológicas e as possibilidades de se obter informações em tempo real estão alterando a maneira como as pessoas se comunicam, se relacionam, e efetuam negócios. Essas mudanças vêm impactando, sobretudo em organizações que atuam no setor do turismo, onde as negociações giram em torno de serviços e informações que não podem ser testados ou experimentados antes da compra.

A Internet vem afetando profundamente os canais de distribuição de viagens e conseqüentemente o papel dos consultores de viagens. As agências de viagens foram surpreendidas pelas companhias aéreas que passaram a negociar diretamente com os clientes para reduzir custos. Este fato contribuiu para que as comissões pagas às agências fossem reduzidas de forma drástica. Diante disso, os negócios de muitas agências de viagens se tornaram inviáveis.

Neste contexto, a $\mathrm{TI}$ se destaca como uma das ferramentas fundamentais para alavancar os negócios das agências de viagens, na medida em que cria estratégias que facilitam o processo de compra, venda e a troca de informações. A TI é considerada como um instrumento de apoio ao setor do turismo, na medida em que proporciona facilidades, tanto para as empresas deste setor, quanto para os consumidores.

Constatou-se através desta pesquisa, que todas as agências entrevistadas estão conectadas à Internet. No entanto, dentro do que é disponibilizado às agencias de viagens em termos de tecnologia, nem todas a utilizam forma extensiva. Das vinte agências de viagens entrevistadas, 55\% 
possuem site, porém somente $10 \%$ realizam vendas on-line. Verificou-se que o principal obstáculo em relação à implementação de novas tecnologias consiste na questão dos custos que são elevados.

Pode-se dizer que as agências que não possuem site também utilizam o comércio eletrônico, pois utilizam o e-mail como suporte à atividade de compra/venda como: cotações de serviços, verificação de disponibilidade e fechamento de reservas.

No que se refere à utilização de estratégias eletrônicas de marketing, nota-se que o e-mail é comum a todas as agências de viagens. $\mathrm{O}$ web tracking é utilizado somente por uma empresa, (5\%). A publicidade on-line é utilizada por três empresas (15\%). A newsletters on-line é utilizada por doze agências de viagens (60\%).

O resultado da análise de dados mostrou um padrão diferenciado no uso da TI por parte das agências de viagens. Constata-se que os recursos da TI podem ser explorados de forma mais intensiva a fim de se atingir um eficiente padrão de uso, aumentado a posição competitiva das agências de viagens.

Quanto aos agentes de viagens, estes devem mudar sua cultura para sobreviver na era da informação. Eles devem ressaltar a importância do trabalho que exercem, agora não mais como simples vendedores de passagens, mas como provedores de informações e serviços especializados. $\mathrm{Na}$ opinião de $35 \%$ dos entrevistados, os agentes de viagens não estão preparados para organizar planos de viagens para os clientes e oferecer aconselhamento e informações especializadas sobre os destinos que vendem.

Sabe-se que a TI dispõe de ferramentas que auxiliam o processo de gestão de uma organização, no entanto, é importante ressaltar que toda gestão deve valorizar os recursos humanos internos. Não se pode dizer que o uso exclusivo da tecnologia, ou mais especificamente de ferramentas operacionais como Internet, sejam suficientes para acompanhar as tendências da globalização e garantir uma administração eficiente. O essencial é aliar o conhecimento dos membros da organização com a tecnologia.

É importante que os agentes de viagens reconsiderem seus negócios, tendo em vista a realidade da globalização, investindo tanto em tecnologia quanto em treinamento de mão-de-obra. É igualmente importante a 
reorganização das agências de viagens através de modernas técnicas de gestão. Essas medidas podem contribuir para a permanência das agências de viagens em um mercado competitivo, além de proporcionar redução de custos e fortalecimento de um produto de maior qualidade a preços mais baixos.

Como uma observação final, percebe-se que o setor do turismo estará cada vez mais vinculado a $\mathrm{TI}$, devido à necessidade de agilizar os serviços, reduzir custos e melhorar o atendimento. Diante desta realidade, as empresas que não aderirem às novas tecnologias estarão sujeitas a enfrentarem muitas dificuldades neste mercado competitivo e provavelmente não sobreviverão.

Como sugestão para pesquisas futuras, pode-se buscar 0 aprofundamento dos seguintes assuntos: i) comparar o padrão de uso das ferramentas de TI pelas agências de viagens do DF com agências de outra localidade e; ii) verificar com os fornecedores de software se existe uma previsão de desenvolvimento de sistemas de comércio eletrônico voltados especificamente ao setor do turismo, pois se constatou que no Brasil há carência desses sistemas e as empresas, em geral, acabam desenvolvendo seus próprios sistemas. 


\section{6 - Referências Bibliográficas}

ABAV - Associação Brasileira dos Agentes de Viagens. Agentes de Viagens e o Turismo. Disponível na Internet em: www.abav.com.br Acesso em out. 2004.

ALBERTIN, A. L. Administração de Informática: Funções e Fatores Críticos de Sucesso. São Paulo: Ed. Atlas, $2^{a}$ ed. 1999.

ALBERTIN, A. L Comércio Eletrônico: Modelos, Aspectos e Contribuições de sua Aplicação. 4a ed. São Paulo, Atlas, 2002.

Banco Mundial, Conhecimento para o Desenvolvimento, Revista Inteligência Empresarial n 1, outubro de 1999, CRIE-COPPE/UFRJ, E-papers Editora, Rio de Janeiro.

BARROS, A. J. S. \& LEHFELD, N. A. S. Fundamentos de Metodologia Científica: Um guia para a iniciação científica. São Paulo: Ed. Makron Books, $2^{\mathrm{a}}$ ed. ampliada, 2000.

BISSOLI, M. A. M. Planejamento turístico municipal com suporte em Sistemas de Informação. São Paulo: Futura, 1999.

CABRINO, T. Marketing de Relacionamento. Disponível em: htpp://portaldomarketing.com.br Acesso em: outubro de 2004.

CARVALHO, L. F. Um Estudo das Técnicas de Comércio e Marketing Eletrônico na world wide web para o setor turístico. 2004. 78 f. Monografia (graduação em Turismo, Gestão-Turismo) Faculdade de Turismo, Universidade do Sul de Santa Catarina, Florianópolis.

CAVALCANTI, M. \& GOMES, E. A Sociedade do conhecimento e a política industrial brasileira. Portal do Ministério do Desenvolvimento, Indústria e Comércio Exterior. Disponível na Internet em: http://www.desenvolvimento.gov.br/sitio/sti/publicacoes/futAmaDilOportunidade s/futIndOpoDesafios.php Acesso em: 18 de out. de 2004.

COSTA, M. A. F. da \& COSTA, M. de F. B. da. Metodologia da Pesquisa: Conceitos e Técnicas. Rio de Janeiro: Ed. Interciência, 2001.

CRUZ, T. Sistemas, Organização \& Métodos: Estudo Integrado das Novas Tecnologias da Informação. São Paulo: Ed. Atlas, 1997. 
DE LA TORRE, O.P. EL turismo, fenómeno social. Ciudad de México: México, Fondo de Cultura Económica, 1992.

DI SERIO, L.C. \& MAIA, M.C. Virtualização do Produto Turístico: um Estudo de Caso. In: CATI 2004 - Congresso Anual de Tecnologia de Informação. SP, 2004.

DICKMAN, S. Tourism: An Introductory Text, Edward Arnold, Caulfield East, 1989.

E-COMMERCE - Dados Estatísticos sobre Internet e Comércio Eletrônico: Disponível em: http://www.e-commerce.org.br/STATS.htm Acesso em: 21/11/2004.

FERNANDES, I.P. \& COELHO, M. F. Economia do Turismo, Teoria e Prática. Rio de Janeiro: Ed. Campus, 2002.

KOTLER, P. Administração de Marketing: a edição do novo milênio. $10^{\mathrm{a}} \mathrm{Ed}$. Prentice Hall, São Paulo, 2000.

LOPES, M. Pronto para decolar. Revista Exame. Mundo digital, 17/11/99. Disponível em: www.uol.com.br/exame/ed701/mdigital1.shl. Link válido em 07.01.01 às 22h14.

MAÑAS, A.V. Administração de sistemas de informação. São Paulo: Érica, 1999.

MARÍN, A. Tecnologia da Informação nas Agências de Viagens: Em Busca da Produtividade e do Valor Agregado. São Paulo: Ed. Aleph, 2004.

MAYA, P.C.C. \& OTERO, W.R.I. A Influência do consumidor na era da Internet. Revista da FAE. Curitiba, v.5, n.1, p.71-81, jan./abr. 2002.

MIDDLETON, V. T. C.; CLARKE, J. Marketing de Turismo: teoria e prática. Tradução da $3^{\mathrm{a}}$ Ed. Editora Campus, Rio de Janeiro, 2002.

O'CONNOR, P. Distribuição da informação eletrônica em turismo e hotelaria/Trade. Porto Alegre: Bookman, 2001.

PORTER, M. E. Strategy and the Internet. Harvard Business Review. March, 2001.

RICHARDSON, R.J. Pesquisa social: métodos e técnicas. São Paulo: Atlas, 1999. 
SANTOS, E. \& HASSAN, A. Computador, 64\% não vêem benefícios em investir - Inclusão digital. Disponível na Internet em: http://www.desa.com.br/desa2/negocios/home neg.php?codsupertopico=43\&c odconteudo $=853$. Acesso em -26 de out. de 2004.

SEYBOLD, P.B. Clientes.com. São Paulo: Makron Books, 2000.

SILVEIRA, A. L. et alli. Tecnologia da Informação em Turismo e Hospitalidade. In: $\left.\right|^{a}$ Jornada Científica de trabalhos Acadêmicos Assesc. Florianópolis - SC, 2002.

Sociedade da Informação no Brasil: Livro Verde / organizado por Tadao Takahashi. - Brasília: Ministério da Ciência e Tecnologia, 2000.

ULYSSÉA, I. M. W. et alli A mídia como oportunidade para o turismo receptivo brasileiro. In: II EMPRETUR - Empreendendo no Turismo. Florianópolis - SC, 2002.

VASSOS, T. Marketing Estratégico na Internet. São Paulo: Makron Books do Brasil, 1998.

YIN, R. Case study research: Design and methods. Thousand Oaks, CA: Sage Publications, Inc., 1994.

YIN, R. Estudo de caso: Planejamento e Métodos. Porto Alegre: Ed. Bookman, 2 ed, 2001. 


\section{Apêndice I}

Este apêndice apresenta as perguntas que foram realizadas junto às vinte agências de viagens que fizeram parte da amostra. Essas agências de viagens são de pequeno porte, operam com poucos funcionários, sendo que $75 \%$ delas operam com menos de 10 funcionários.

\section{QUESTIONÁRIO}

\section{Pesquisa sobre a utilização da Internet nas agências de turismo.}

1 - Em que ano a agência de viagens iniciou suas atividades?

2) - Quantos funcionários a agência possui?

Em que ano a agência conectou-se à Internet?

4 - A agência possui site ou utiliza a Internet apenas para troca de e-mails?

5) Através do site é possível realizar todas as transações on-line, inclusive pagamento?

( ) $\operatorname{Sim}($ ) Não

6 - A homepage da agência está inserida em sites de busca?

( ) Sim ( ) Não

7 - A agência possui banners ou links em sites institucionais?

( ) Sim ( ) Não 
8 - Os profissionais que atuam nas agências de viagens estão capacitados para trabalhar com as ferramentas da TI?
( ) Sim ( ) Não

9) Os profissionais recebem treinamento?

( ) Sim ( ) Não

10 - Os agentes de viagens estão preparados para organizar planos de viagens para os clientes e oferecer aconselhamento e informações especializadas sobre os destinos, ou agem, em geral, somente como vendedores de passagens?

( ) Sim ( ) Não

11 - Qual é o meio utilizado pela agência para estar sempre atualizada em termos de inovações tecnológicas?

12) Existem obstáculos para implementação das novas tecnologias? Quais são?

13) - A agência utiliza algum método para fidelizar os clientes? Qual?

( ) $\operatorname{Sim}($ ) Não

14) A agência utiliza o comercio eletrônico?

( ) Sim ( ) Não

15) A agência conhece as estratégias de promoção eletrônica de marketing como:
( ) Website
( ) Web tracking
( ) Publicidade on line
( ) Newsletters on line
( ) E-mail e SMS 